\title{
sigE facilitates the adaptation of Bordetella bronchiseptica to stress conditions and lethal infection in immunocompromised mice
}

\author{
Sarah E Barchinger ${ }^{1 \dagger}$, Xuqing Zhang ${ }^{2,3+}$, Sara E Hester ${ }^{2}$, Maria E Rodriguez ${ }^{4}$, Eric T Harvill ${ }^{*}$ and Sarah E Ades ${ }^{1 *}$
}

\begin{abstract}
Background: The cell envelope of a bacterial pathogen can be damaged by harsh conditions in the environment outside a host and by immune factors during infection. Cell envelope stress responses preserve the integrity of this essential compartment and are often required for virulence. Bordetella species are important respiratory pathogens that possess a large number of putative transcription factors. However, no cell envelope stress responses have been described in these species. Among the putative Bordetella transcription factors are a number of genes belonging to the extracytoplasmic function (ECF) group of alternative sigma factors, some of which are known to mediate cell envelope stress responses in other bacteria. Here we investigate the role of one such gene, sigE, in stress survival and pathogenesis of Bordetella bronchiseptica.

Results: We demonstrate that sigE encodes a functional sigma factor that mediates a cell envelope stress response. Mutants of B. bronchiseptica strain RB50 lacking sigE are more sensitive to high temperature, ethanol, and perturbation of the envelope by SDS-EDTA and certain $\beta$-lactam antibiotics. Using a series of immunocompromised mice deficient in different components of the innate and adaptive immune responses, we show that SigE plays an important role in evading the innate immune response during lethal infections of mice lacking B cells and T cells. SigE is not required, however, for colonization of the respiratory tract of immunocompetent mice. The sigE mutant is more efficiently phagocytosed and killed by peripheral blood polymorphonuclear leukocytes (PMNs) than RB50, and exhibits decreased cytotoxicity toward macrophages. These altered interactions with phagocytes could contribute to the defects observed during lethal infection.

Conclusions: Much of the work on transcriptional regulation during infection in B. bronchiseptica has focused on the BvgAS two-component system. This study reveals that the SigE regulon also mediates a discrete subset of functions associated with virulence. SigE is the first cell envelope stress-sensing system to be described in the bordetellae. In addition to its role during lethal infection of mice deficient in adaptive immunity, our results indicate that SigE is likely to be important for survival in the face of stresses encountered in the environment between hosts.
\end{abstract}

Keywords: B. bronchiseptica, Extracytoplasmic function sigma factor, Cell envelope stress, Pathogenesis

\footnotetext{
*Correspondence: eth10@psu.edu; ades@psu.edu

${ }^{\dagger}$ Equal contributors

${ }^{2}$ Department of Veterinary and Biomedical Sciences, Pennsylvania State

University, W210 Millennium Science Complex, University Park, PA 16802,

USA

Full list of author information is available at the end of the article
}

\section{Biomed Central}

(c) 2012 Barchinger et al.; licensee BioMed Central Ltd. This is an Open Access article distributed under the terms of the Creative Commons Attribution License (http://creativecommons.org/licenses/by/2.0), which permits unrestricted use, distribution, and reproduction in any medium, provided the original work is properly cited. 


\section{Background}

The cell envelope of bacterial pathogens is critical for survival both in a host during infection and in the environment outside of the host. As the interface between the bacterium and the outside milieu, the cell envelope acts as a barrier protecting the cell against extracellular hazards. Cell envelope structures are also intimately involved in the formation of contacts with host tissues during infection. To safeguard this important compartment, gram-negative bacteria possess an array of stress responses that sense conditions in the cell envelope and alter gene expression to ensure its integrity [1,2]. In many bacterial pathogens, cell envelope stress responses play a multifaceted role. They provide protection against damage caused by components of the immune system, such as complement and antimicrobial peptides that target the cell envelope [3-5]. They regulate the expression of chaperones required for proper assembly of cell envelope-associated structures, including outer membrane porins, pili, and fimbrae [3,6,7]. In addition, cell envelope stress responses can sense the environment around the bacterium and regulate the expression of virulence factors in response to specific cues, ensuring that these factors are expressed at the proper time and location in the host $[2,8]$. Despite their importance, no cell envelope stress responses have yet been identified or implicated in pathogenesis in Bordetella species.

Bordetella bronchiseptica is a respiratory pathogen that is closely related to Bordetella pertussis and Bordetella parapertussis, the causative agents of whooping cough in humans $[9,10]$. B. bronchiseptica causes a range of diseases in various mammals that can be chronic, difficult to completely eradicate, and of variable virulence [11-13]. It is the etiological agent of atrophic rhinitis in swine, kennel cough in dogs, and snuffles in rabbits [12,13]. Documented human infections, generally traced to an animal source, have been observed in immunocompromised individuals, and can be serious, systemic infections [11,14].

The B. bronchiseptica, B. pertussis and B. parapertussis genomes encode a large number of putative transcription factors relative to their overall genome size [15], suggesting that these pathogens have the capacity to extensively regulate gene expression in response to environmental and physiological changes. Despite this finding, only a few Bordetella transcription factors have been studied in any detail [16-20]. Among the predicted transcription factors is an ortholog of the cell envelope stress response sigma factor, $\sigma^{\mathrm{E}}$, of $E$. coli. In bacteria, sigma factors are the subunits of bacterial RNA polymerases required for specific promoter recognition and transcription initiation [21]. Alternative sigma factors, like $\sigma^{\mathrm{E}}$, are activated in response to specific stresses and rapidly reprogram gene expression by replacing the housekeeping sigma factor and directing RNA polymerase to the genes in their regulons [21,22].

$\sigma^{\mathrm{E}}$ belongs to the RpoE-like group of extracytoplasmic function (ECF) sigma factors that have been increasingly implicated as key factors contributing to both bacterial stress responses and virulence [23,24]. These sigma factors are widely distributed across bacterial phyla. Where studied, they direct a diverse set of stress responses primarily targeted to the cell envelope $[2,8,24,25]$. In E. coli and Salmonella enterica serovar Typhimurium, $\sigma^{\mathrm{E}}$ controls many genes whose products are required for the proper expression of outer membrane porins and LPS $[26,27]$. During infection, $\sigma^{\mathrm{E}}$ of $S$. Typhimurium is required for survival and proliferation in epithelial and macrophage cell lines, and in the presence of antimicrobial peptides $[6,28,29]$. In Pseudomonas aeruginosa, the $\sigma^{\mathrm{E}}$ homologue, AlgU, controls the expression of the exopolysaccharide alginate and conversion to mucoidy. $\mathrm{AlgU}$ is constitutively activated in many clinical isolates from cystic fibrosis patients [30,31]. In addition, $\sigma^{\mathrm{E}}$ is required for the viability of some bacterial species, but not others. The gene encoding $\sigma^{\mathrm{E}}$ is essential in $E$. coli and Yersinia enterocolitica, but is dispensable in the closely related species $S$. Typhimurium $[6,32,33]$. These observations suggest that the functions of $\sigma^{\mathrm{E}}$ orthologs have been adapted to combat the challenges each organism faces in its particular environmental niche. By exploring the role of $\sigma^{\mathrm{E}}$ in diverse bacterial species, we can learn which aspects of this widespread regulatory pathway are universally conserved and which have diverged over the course of evolution.

Here we show that the B. bronchiseptica $\sigma^{\mathrm{E}}$ ortholog, encoded by the gene sigE (BB3752), is an active sigma factor that mediates a cell envelope stress response. This is the first demonstration of an envelope stress-sensing system in Bordetella species. Using a murine infection model, we demonstrate that SigE plays an important role during lethal infection in mice lacking adaptive immunity, but not in respiratory tract colonization. This finding has important implications for human disease, given the observation that $B$. bronchiseptica can cause serious systemic infections in immunocompromised humans $[11,14]$. This study suggests that SigE is a critical factor in this process, in addition to the BvgAS master virulence regulatory system.

\section{Results}

sigE encodes an active sigma factor

The sigE gene of B. bronchiseptica shares a number of conserved residues with other members of the RpoE-like sigma factors, including those in the DNA-binding regions (Figure 1A) [24]. To determine if sigE encodes an active sigma factor, we asked whether it could direct transcription from the $\sigma^{\mathrm{E}}$-dependent rpoHP3 promoter 


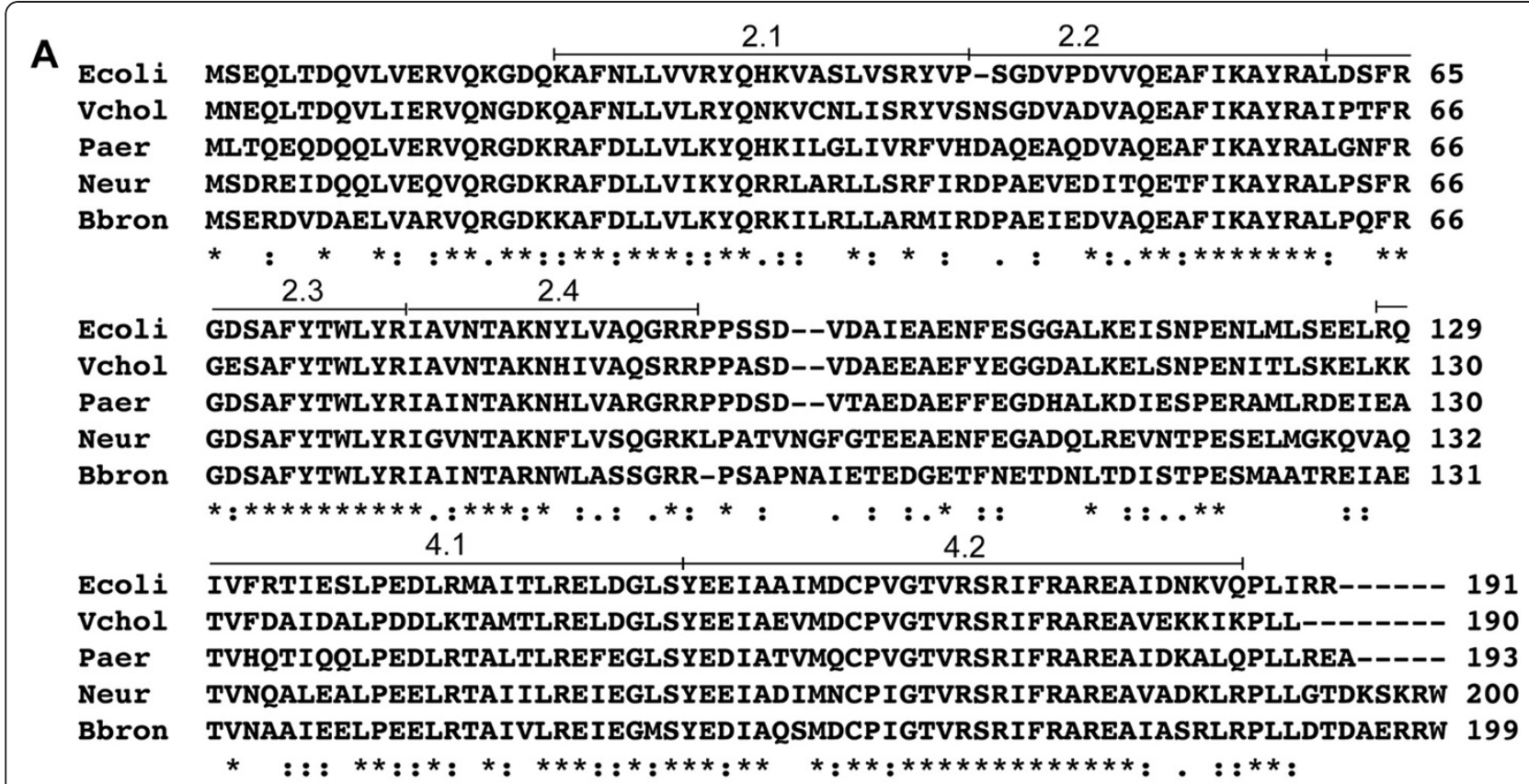

B

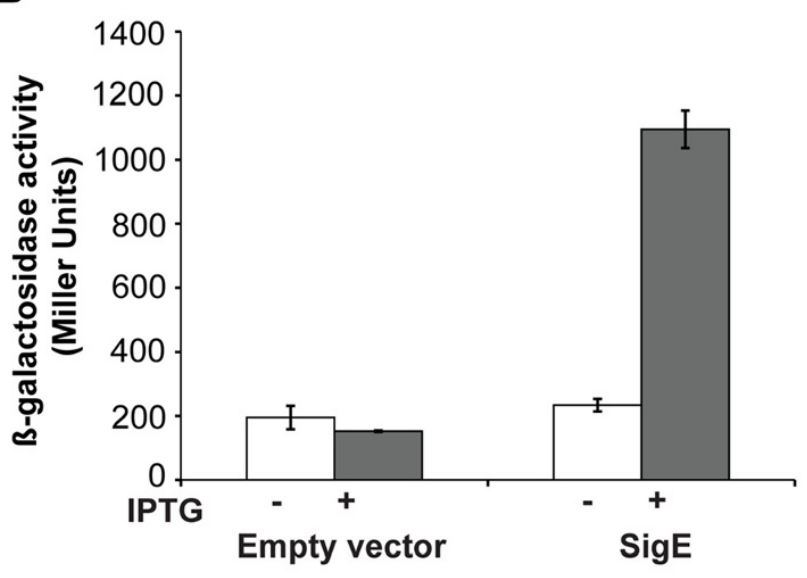

C
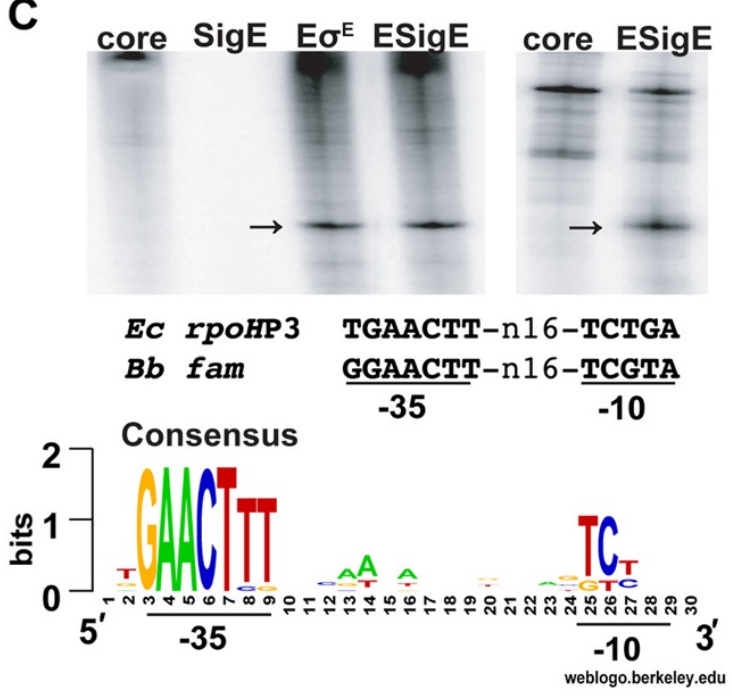

Figure 1 B. bronchiseptica SigE is a functional sigma factor. (A) Amino acid sequence alignment of RpoE- like sigma factors from Escherichia coli (Ecoli), Vibrio cholerae (Vchol), Pseudomonas aeruginosa (Paer), Nitrosomonas europaea (Neur) and B. bronchiseptica (Bbron) using ClustalW2 (EMBL-EBI). Asterisks indicate identity, two dots indicate strong similarity, and one dot indicates weak similarity between amino acid residues. Conserved sigma factor regions 2.1-2.4 and 4.1-4.2 [22] are indicated above the alignment. Regions 2.3, 2.4, and 4.2 are responsible for promoter recognition [22]. (B) $\beta$-galactosidase activity from the E. coli rpoHP3-lacZ reporter increases when B. bronchiseptica sigE expression is induced from plasmid pSEB006 in strain SEA5005 by the addition of IPTG. No increase is seen upon IPTG addition to the control strain, SEA008, containing the empty vector. The observed difference in the amount of $\beta$-galactosidase activity between the two strains in the presence of IPTG is statistically significant ( $P$ value $<0.001)(\mathbf{C})$ In vitro transcription from a supercoiled plasmid template containing the $E$. coli $\sigma^{\mathrm{E}}$-dependent rpoHP3 promoter with E. coli core RNA polymerase (core), SigE alone, E⿰ ${ }^{\mathrm{E}}$, and ESigE (left panel). In vitro transcription from a linear template containing the promoter region of B. bronchiseptica fam, with E. coli core RNAP alone (core), or ESigE (right panel). Arrows indicate transcripts from the rpoHP3 and fam promoters. Below, an alignment of the E. coli rpoHP3 and B. bronchiseptica fam promoter sequences and a sequence logo showing the consensus promoter for RpoE-like (ECF02) sigma factors from Staron et al. [24].

in $E$. coli. This promoter shares a high degree of similarity with a consensus promoter proposed for the RpoE-like sigma factors that was determined from both experimental data and predicted promoter sequences (Figure 1C)
[24,27]. The sigE gene from B. bronchiseptica strain RB50 was cloned into the pTrc99a expression plasmid and transformed into a derivative of E. coli MG1655 that carries an rpoHP3::lac $Z$ reporter gene fusion integrated on 
the chromosome [34]. When sigE expression was induced, LacZ activity increased, indicating that SigE can initiate transcription from this promoter (Figure 1B). Furthermore, we found that the gene encoding $\sigma^{\mathrm{E}}, r p o E$, which is essential for viability in E. coli, could be deleted when $\operatorname{sig} E$ was overexpressed (data not shown, see Materials and Methods).

To provide additional evidence that SigE is a functional sigma factor, N-terminally His-tagged SigE was purified and tested for its ability to initiate transcription in vitro from the E. coli rpoHP3 promoter. Holoenzyme formed with SigE and E. coli core RNA polymerase (ESigE) was able to direct transcription and produced a transcript of equivalent length to that generated by $E$. coli $\mathrm{E \sigma}^{\mathrm{E}}$ (Figure $1 \mathrm{C}$ ). The region immediately upstream of the B. bronchiseptica rpoH homologue, encoded by the fam gene, contains a sequence that is similar to the proposed $\sigma^{\mathrm{E}}$-dependent consensus promoter, suggesting that B. bronchiseptica rpoH is regulated by SigE. Indeed, SigE was able to direct transcription from the putative fam promoter region in vitro (Figure 1C). Taken together, these results demonstrate that SigE is a functional sigma factor and can initiate transcription from promoter sequences similar to those utilized by other members of the RpoE-like sigma factor family.

\section{sigE contributes to the $B$. bronchiseptica stress response}

To investigate the role of SigE in B. bronchiseptica, an in-frame deletion of the $\operatorname{sig} E$ gene was constructed in RB50 (RB50 $\Delta s i g E)$ that removed 176 out of 200 codons of the gene, leaving 22 and 2 codons at the $5^{\prime}$ and $3^{\prime}$ ends of the gene, respectively. The deletion was confirmed by PCR and Southern blotting methods (data not shown). $\sigma^{\mathrm{E}}$ orthologs are essential in some bacteria, including E. coli and $Y$. enterocolitica [33,35], yet are not required for viability in many other species, such as $S$. Typhimurium, P. aeruginosa, and Burkholderia pseudomallei $[6,36,37]$. Deletions of B. bronchiseptica sigE were readily obtained, suggesting that it falls in the latter class, and is not essential for viability. Furthermore, RB50 $\operatorname{sigE}$ grew at a rate similar to that of RB50 under standard growth conditions $\left(37^{\circ} \mathrm{C}\right.$ in Stainer-Scholte broth) (Figure 2A).

To investigate whether SigE mediates a cell envelope stress response in B. bronchiseptica, we used disk diffusion assays to compare the sensitivity of RB50 and RB50 $\operatorname{sigE}$ to several chemicals that compromise cell envelope integrity and a series of antibiotics that block different steps in peptidoglycan synthesis. The sigE mutant was more sensitive than the wild-type strain to the detergent SDS in combination with EDTA (Figure 2B). The sigE mutant was also more sensitive than wild-type RB50 to the antibiotics mecillinam and ampicillin (Figure 2B), whereas sensitivity to meropenem, aztreonam, and imipenem was not affected (data not shown). Unlike $\sigma^{E}$ orthologs in other bacteria, SigE was not required for resistance to the cationic antimicrobial peptide polymyxin $\mathrm{B}$, which targets bacterial membranes, or to osmotic stress (Figure 2B and data not shown) [6,36,38,39]. RB50 $\Delta$ sigE and RB50 were also equally sensitive to antibiotics that inhibit cytoplasmic processes such as translation (chloramphenicol, erythromycin, kanamycin, tetracycline), transcription (rifampicin), and cytoplasmic enzymes such as DNA gyrase (nalidixic acid), and dihydrofolate reductase (trimethoprim) (data not shown). This lack of sensitivity to multiple antibiotics suggests that the sigE mutation does not lead to an overall increase in the permeability of the outer membrane, which would allow more of the antibiotic to enter the cell. These results show that SigE is important for survival in response to specific types of damage to the cell envelope, such as disruption of cellular membranes caused by SDS/EDTA and interference with synthesis of the peptidoglycan layer caused by ampicillin and mecillinam.

We next asked if sigE is important for survival following a shift to high temperature, which perturbs both the cell envelope and cytoplasm. RB50 and RB50 $\Delta s i g E$ were grown at $37^{\circ} \mathrm{C}$ to an $\mathrm{OD}_{600}$ of 0.4 , then shifted to $50^{\circ} \mathrm{C}$, a lethal temperature for $B$. bronchiseptica. Cell viability, assessed by $\mathrm{CFU} / \mathrm{ml}$, was measured after the shift to $50^{\circ}$ C. Survival of the RB50 $\Delta$ sigE strain was lower than that of RB50 (Figure 2C). In attempting to complement this phenotype, we found that plasmid-encoded sigE did not restore survival during heat shock (data not shown), although it did complement other phenotypes, as described below. Similar variability in complementation of a $\sigma^{\mathrm{E}}$ mutant by a plasmid-encoded $r p o E$ gene has been seen in other bacteria $[29,36,40,41]$. Work from Burkholderia cenocepacia showed that expressing $\sigma^{\mathrm{E}}$ from a plasmid actually increased sensitivity to heat stress [36]. In $S$. Typhimurium, an rpoE mutant was sensitive to paraquat and did not survive in stationary phase under anaerobic conditions. Expression of rpoE from a plasmid partially complemented the former phenotype, but not the latter [29]. Because the anti-sigma factor that regulates $\sigma^{\mathrm{E}}$ activity was not included in any of these instances, it is likely that proper regulation of SigE activity is required for optimal response to particular stresses, not merely excess SigE activity, complicating complementation experiments.

Another aspect of the classical heat shock response is thermotolerance. When bacteria are exposed to an elevated but nonlethal temperature, heat shock responses are induced, resulting in increased production of chaperones and proteases that refold or degrade unfolded proteins [42]. Consequently, the cells are preloaded with protective factors and exhibit increased survival following a subsequent shift to a lethal temperature [42]. To investigate the 
A

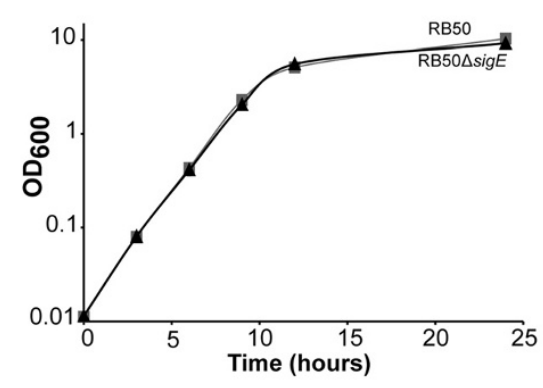

C

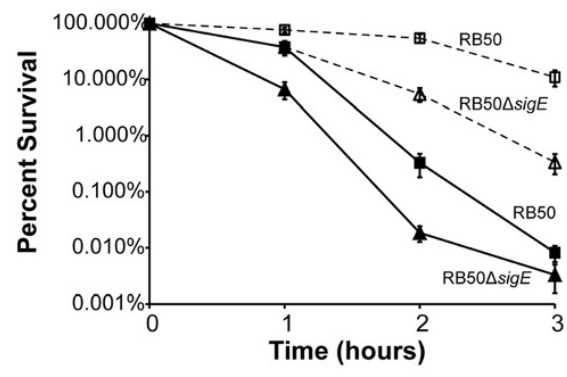

B

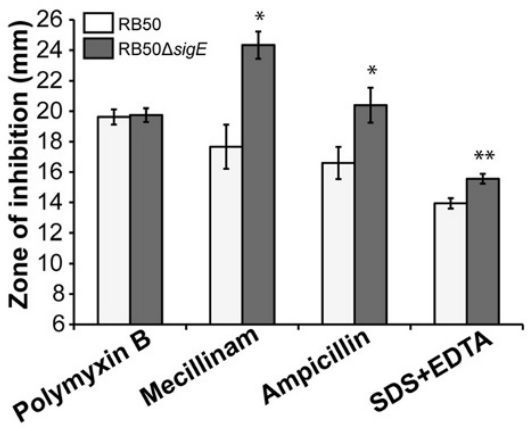

D

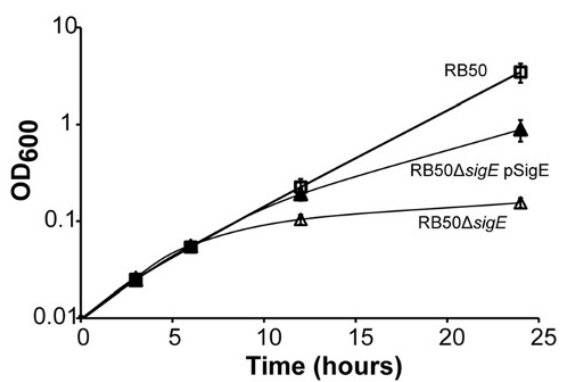

Figure 2 Role of SigE in response to environmental stresses. (A) RB50 (squares) and RB50 $\triangle$ sigE (triangles) grow similarly at $37^{\circ} \mathrm{C}$ in StainerScholte broth. (B) RB50 $\triangle$ sigE (white bars) is more sensitive than RB50 (grey bars) to treatment with $100 \mu \mathrm{g}$ mecillinam, $10 \mu \mathrm{g}$ ampicillin, or $750 \mu \mathrm{g}$ SDS and $2.9 \mu \mathrm{g}$ EDTA, but is similarly sensitive to treatment with $300 \mathrm{IU}$ polymyxin B in disk diffusion assays. The average diameters of the zones of inhibition \pm SE from at least three independent experiments are shown. The disk diameter was $6 \mathrm{~mm}$. The observed differences between the zones of inhibition for RB50 and the sigE mutant are statistically significant for mecillinam, ampicillin, and SDS-EDTA (* indicates a P-value of $<0.05$; ** indicates a P-value $<0.01$ ). (C) RB50 $\triangle$ sigE (triangles) is more sensitive than RB50 (squares) to heat shock (solid line, filled symbols) caused by shifting cultures from $37^{\circ} \mathrm{C}$ to $50^{\circ} \mathrm{C}$. RB50 $\triangle$ sigE also exhibits reduced thermotolerance (dashed line, open symbols), surviving less well than RB50 when adapted first to $40^{\circ} \mathrm{C}$ before a shift to $50^{\circ} \mathrm{C}$. The mean percent survival \pm SE of fifteen independent experiments for each strain is shown. (D) RB50 $\triangle$ sigE containing the empty cloning vector pEV (open triangles) is more sensitive to treatment with $3 \%$ ethanol than RB50 pEV (squares). Expression of plasmid-encoded SigE (RB50 $\triangle$ sigE pSigE) restores growth in 3\% ethanol (filled triangles) to near wild-type levels at the 6 and 12 hour time points and partially restores growth at the 24 hour time point. The mean $\mathrm{OD}_{600} \pm \mathrm{SE}$ of at least four independent experiments is shown for each strain.

role of SigE in this phenomenon, RB50 and RB50 sigE were grown to an $\mathrm{OD}_{600}$ of 0.1 at $37^{\circ} \mathrm{C}$, shifted to $40^{\circ} \mathrm{C}$ for 90 min, then shifted to $50^{\circ} \mathrm{C}$. RB50 cultures incubated at $40^{\circ} \mathrm{C}$ before $50^{\circ} \mathrm{C}$ survived better at all time points than those directly shifted from $37^{\circ} \mathrm{C}$ to $50^{\circ} \mathrm{C}$. For example, $54 \%$ of the RB50 cells pre-adapted at $40^{\circ} \mathrm{C}$ survived two hours after the shift to $50^{\circ} \mathrm{C}$ (Figure 2C) compared to $0.1 \%$ survival for those shifted directly from $37^{\circ} \mathrm{C}$ to $50^{\circ} \mathrm{C}$ (Figure 2C). RB50 $\Delta$ sigE pre-adapted at $40^{\circ} \mathrm{C}$ also survived better at $50^{\circ} \mathrm{C}$ than when directly shifted from $37^{\circ} \mathrm{C}$ to $50^{\circ} \mathrm{C}$. However, only $38 \%$ of the RB50 $\Delta$ sigE cells survived after one hour (compared to $76 \%$ of the wild-type RB50), and 5\% survived after two hours at $50^{\circ} \mathrm{C}$ (Figure $2 \mathrm{C}$ ). These results demonstrate that $B$. bronchiseptica exhibits a classical thermotolerance response and that SigE contributes to this response.
Both ethanol and heat shock lead to protein unfolding and membrane perturbation and often elicit similar stress responses [43]. To test the role of $s i g E$ in response to ethanol stress, RB50 and RB50 $\Delta$ sigE were subcultured from mid-exponential-phase cultures into fresh StainerScholte broth with or without 3\% ethanol. Both strains grew similarly in medium without ethanol, as noted above. RB50 grew significantly slower in medium containing 3\% ethanol than in medium without ethanol (compare the growth curve for RB50 in Figure 2D with that in Figure 2A), but eventually reached a cell density only slightly below that of cultures grown without ethanol. In contrast, the cell density of RB50 $\Delta$ sigE grown in the presence of $3 \%$ ethanol never surpassed an $\mathrm{OD}_{600}$ of around 0.1, even after 24 hours. Expression of plasmidencoded sigE in RB50 $s$ sigE complemented this 


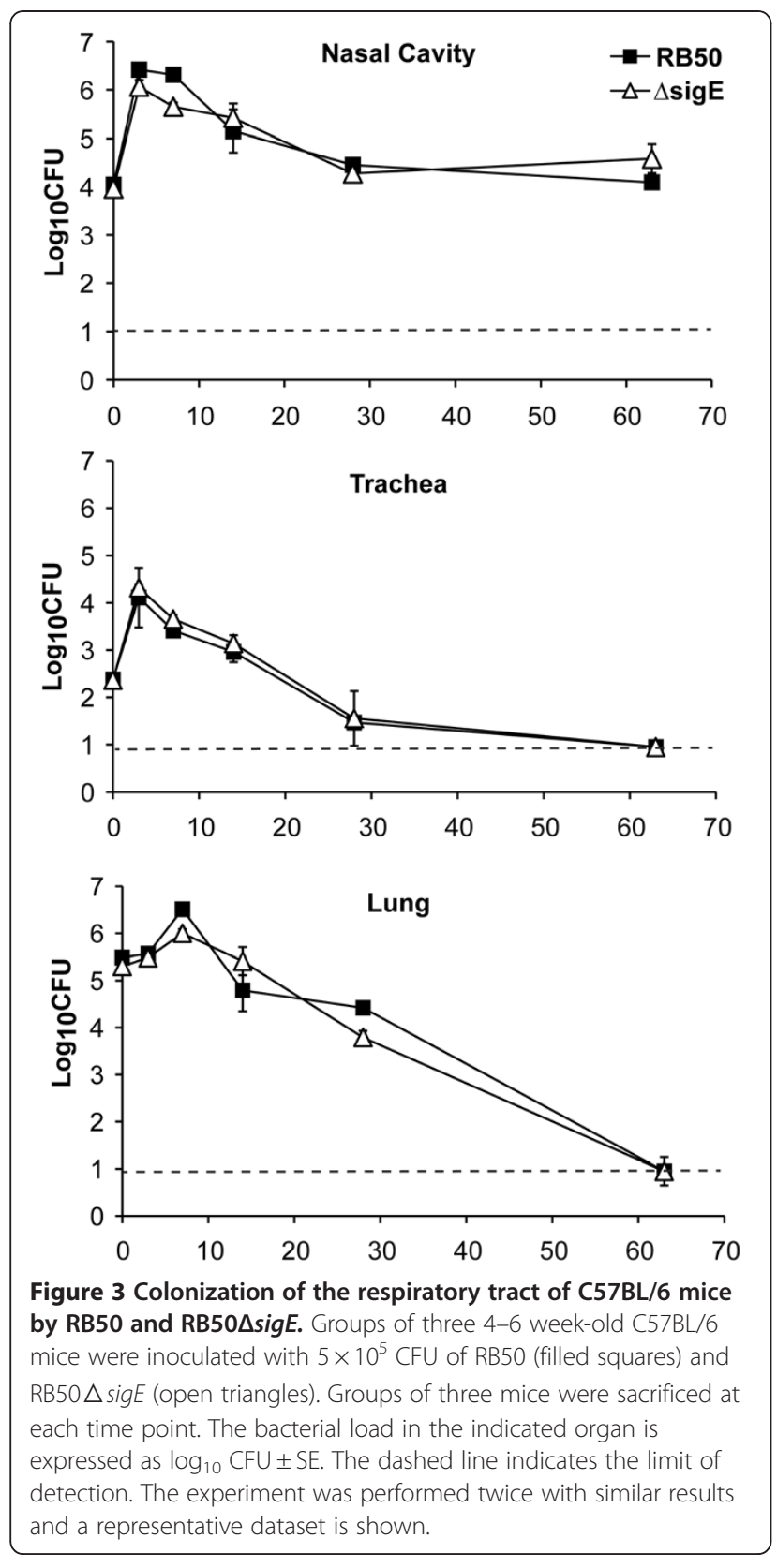

phenotype, restoring growth in medium with 3\% ethanol to nearly that of RB50 (Figure 2D), indicating that sigE is required for survival during ethanol stress.

$\sigma^{\mathrm{E}}$ homologues have also been found to play a role during oxidative stress in S. Typhimurium and Burkholderia pseudomallei $[29,41]$. However, in disk diffusion assays, SigE was not required for survival in the presence of hydrogen peroxide or paraquat, two inducers of oxidative stress (data not shown). Either SigE is not involved in combating oxidative stress in B. bronchiseptica, or other oxidative-stress responsive pathways compensate for SigE when it is absent.
Growth in the murine respiratory tract is not affected by the lack of sigE

B. bronchiseptica RB50 colonizes the respiratory tract of immunocompetent mice, causing an asymptomatic infection that is eventually cleared by the immune system. To determine whether B. bronchiseptica SigE contributes to colonization and persistence in the respiratory tract, groups of C57BL/6 mice were inoculated with RB50 or RB50 $\operatorname{sigE}$. Colonization was measured in the nasal cavity, trachea, and lung on days $0,3,7,14,28$ and 63 post-inoculation. Both wild-type and sigE-deficient RB50 colonized the nasal cavity at comparable levels, peaking on day 3 post-inoculation, and stabilizing at about $10^{4-5} \mathrm{CFU}$ by 2 weeks post-inoculation (Figure 3 ). Both strains also showed similar colonization kinetics in the lower respiratory tract of C57BL/6 mice, peaking in numbers on days 3 and 7 post-inoculation in the trachea and lungs, respectively, and declining thereafter, with complete clearance in both organs by day 63 post-inoculation (Figure 3). These data indicate that B. bronchiseptica SigE is not required for colonization or persistence in the murine respiratory tract.

\section{SigE contributes to lethal B. bronchiseptica infection in} mice lacking $B$ cells and T cells, but not in mice lacking TLR4 or TNF-a

B. bronchiseptica has been observed to cause a range of disease including bronchitis, lethal pneumonia, and even systemic infection $[11,12]$. Mice with defined immune deficiencies are particularly susceptible to different forms of disease [44-46], facilitating assessment of the roles of specific bacterial factors/functions in interactions with different aspects of the host immune response.

Mice lacking key components of innate immunity, either TLR4 or TNF- $\alpha$, were challenged with RB50 or RB50 $\Delta$ sigE and signs of severe disease were monitored. Consistent with published studies, TLR4 ${ }^{\text {def }}$ and TNF- $\alpha^{-/-}$ mice inoculated with $10^{5} \mathrm{CFU}$ of RB50 quickly developed signs of lethal bordetellosis such as ruffled fur, hunched posture, decreased activity, and difficulty breathing, and succumbed 2 to 5 days post-inoculation [46,47]. Mice challenged with RB50 $\Delta$ sigE also showed similar signs of disease and time to death (data not shown). In a separate experiment, TLR4 ${ }^{\text {def }}$ mice and TNF- $\alpha^{-/-}$mice infected with RB50 or RB50 $\Delta$ sigE that were still alive by day 3 post-inoculation were dissected for bacterial enumeration in the respiratory as well as systemic organs. Both wild-type and sigE-deficient RB50 colonized the lungs of TLR4 ${ }^{\text {def }}$ mice at $10^{7-8} \mathrm{CFU}$, which was almost 1000 -fold higher than in the lungs of TLR ${ }^{\text {suf }}$ mice. Moreover, both strains colonized the systemic organs in TLR4 ${ }^{\text {def }}$, but not TLR4 ${ }^{\text {suf }}$ mice (data not shown). Both strains also grew to higher numbers in the 
lungs of $\mathrm{TNF}-\alpha^{-/-}$mice than in the lungs of $\mathrm{C} 57 \mathrm{BL} / 6$ mice and were recovered from systemic organs only in TNF- $\alpha^{-/-}$mice (data not shown). These data indicate that SigE is not required for $B$. bronchiseptica to cause lethal infection and colonize systemic organs in mice lacking TLR4 or TNF- $\alpha$.

$\mathrm{B}$ and $\mathrm{T}$ cell-deficient $\operatorname{Rag} 1^{-/-}$mice succumb to $B$. bronchiseptica infection, and death is associated with systemic spread of the infection [48]. To assess the role of SigE during infection in hosts deficient in adaptive immunity, groups of $\operatorname{Rag} 1^{-1-}$ mice were inoculated with $5 \times 10^{5} \mathrm{CFU}$ of RB50 or RB50 $\Delta s i g E$. Rag1 $1^{-/-}$mice inoculated with RB50 showed symptoms of lethal bordetellosis on day 13 post-inoculation and succumbed between days 14-35 post-inoculation (Figure 4A). However, Rag1 $1^{-1-}$ mice inoculated with RB50 $\Delta$ sigE survived without any

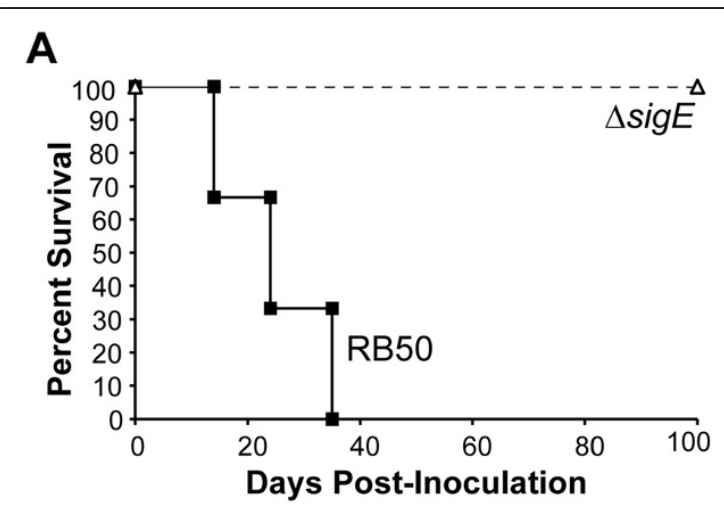

B

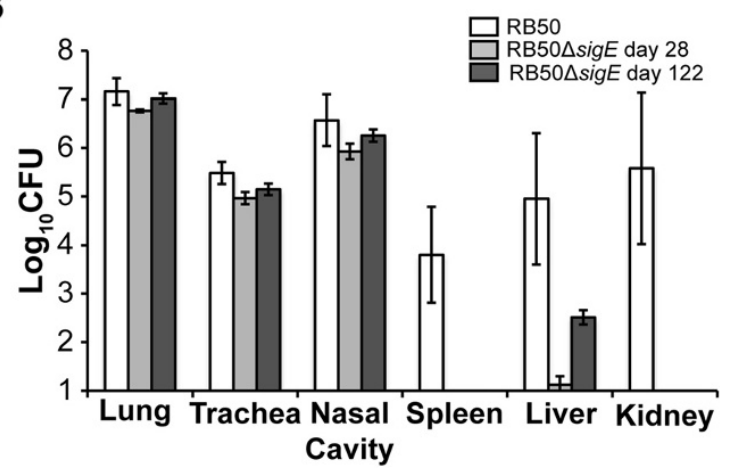

Figure 4 Survival and systemic colonization of Rag $1^{-/-}$mice following infection with RB50 and RB50 $\Delta$ sigE. (A) Groups of Rag1 ${ }^{-}$mice $(n=6)$ were inoculated with $5 \times 10^{5}$ CFU of RB50 (solid line with filled squares) or RB50 $\triangle$ sigE (dashed line with open triangles) and monitored for survival. (B) Groups of four Rag $1^{-/-}$mice were inoculated with $5 \times 10^{5}$ CFU of RB50 (white bars) or RB50 $\triangle$ sigE (light grey bars) and dissected on day 28 post-inoculation for bacterial enumeration in the indicated organs. In a separate experiment, Rag1

-/- mice inoculated with RB50 $\triangle$ sigE were euthanized for bacterial numbers in the indicated organs on day 122 post-inoculation (dark grey bars). The bacterial load is expressed as $\log _{10}$ CFU \pm SE. Limit of detection is indicated as the bottom of the $y$-axis. overt signs of disease and were euthanized on day 122 post-inoculation. The nasal cavity, trachea, lungs, spleen, liver, and kidneys of these mice were excised to enumerate bacterial loads. Although $10^{5-7}$ CFU of RB50 $\Delta$ sigE were recovered from the respiratory tract, this strain failed to colonize the spleen or kidney, and only $300 \mathrm{CFU}$ were recovered from the liver (Figure 4B, dark gray bars). In a separate experiment, RB50 and RB50 $\Delta$ sigE-inoculated $\operatorname{Rag} 1^{-/-}$mice were sacrificed on day 28 post-inoculation, when some of the RB50challenged mice were still alive. The bacterial loads of RB50 and RB50 $\Delta$ sigE in the respiratory tract on day 28 post-inoculation were similar, about $10^{5-7} \mathrm{CFU}$. At this time, $10^{4-6} \mathrm{CFU}$ of RB50 were recovered from liver, spleen, and kidney (Figure 4B, white bars). RB50 $\Delta$ sigE, however, failed to colonize the spleen, kidney or liver (Figure 4B, light gray bars). These results demonstrate that SigE is required for lethal infection by B. bronchiseptica in $\mathrm{Rag} 1^{-/-}$mice.

The failure of RB50 $\Delta$ sigE to colonize distal organs of Rag1 $1^{-/-}$mice suggests that this mutant may be defective in getting into or survival in the bloodstream and/or systemic organs. The bloodstream includes many important bactericidal factors of the host immune system, including complement and phagocytes. We first examined whether B. bronchiseptica lacking sigE is more susceptible to complement-mediated killing. 500 CFU of RB50, $\mathrm{RB} 50 \Delta s i g E$, or $\mathrm{RB} 50 \Delta w b m$, a strain lacking O-antigen, which is known to be susceptible to complement [48], were incubated at $37^{\circ} \mathrm{C}$ for one hour in PBS with $20 \%$ complement-active or complement-inactive serum from naive mice. The survival of RB50 $\Delta$ sigE and RB50 was not affected by the presence of either serum (data not shown). In contrast, the RB50 $\Delta w b m$ strain was almost completely killed by complement-active, but not complement-inactive serum $(0.7 \%$ survival in the presence of complement-active serum compared to $100 \%$ survival in the presence of complement-inactive serum). The observation that RB50 $\Delta$ sigE survived in the presence of serum without $B$. bronchiseptica-specific antibodies indicates that the defect in causing systemic infection in mice lacking $\mathrm{B}$ and $\mathrm{T}$ cells is not due to failure to survive the antimicrobial components in serum, including complement.

\section{SigE contributes to cytotoxicity to macrophages}

We further tested whether RB50 $\Delta$ sigE interacts differently than RB50 with another major bactericidal component in the bloodstream, phagocytes. B. bronchiseptica is cytotoxic to macrophages, and this toxicity has been attributed to the activities of the type three secretion system (TTSS) [49]. To test the role of SigE in macrophage cytotoxicity, RAW264.7 murine macrophages were incubated for 4 hours at an MOI of 10 with RB50, 
RB50 lacking sigE, or RB50 lacking a functional TTSS (WD3). In this experiment, both the RB50 and RB50 $\Delta$ sigE strains contained the empty cloning vector $\mathrm{pEV}$ to allow direct comparisons with the complemented strain, RB50 $\Delta$ sigE pSigE. Cytotoxicity was determined by measuring $\mathrm{LDH}$ release from the treated macrophages. WD3 caused little cytotoxicity, similar to treatment with medium alone. RB50 $\Delta$ sigE pEV caused approximately $50 \%$ less cytotoxicity than wild-type RB50 pEV (Figure 5). This defect in cytotoxicity was complemented by supplying the $\operatorname{sig} E$ gene on the plasmid pSigE (Figure 5), indicating that loss of $\operatorname{sig} E$ negatively impacts the ability of RB50 to kill macrophages.

\section{RB50 $\Delta$ sigE is more efficiently phagocytosed and killed by PMNs}

To test if RB50 $\Delta$ sigE is more susceptible to another bactericidal mechanism, phagocytosis by peripheral blood polymorphonuclear leukocytes (PMNs), RB50 and RB50 $\Delta$ sigE were incubated with freshly isolated human PMNs and attachment to, phagocytosis by, and killing by these cells were measured. PMNs bound RB50 $\Delta$ sigE more efficiently than RB50 (Figure 6A), and significantly more RB50 $\Delta$ sigE than RB50 were phagocytosed by PMNs (Figure 6B). However, the number of viable intracellular RB50 $\Delta$ sigE was $\sim 50 \%$ of the numbers of viable RB50 (Figure 6C, left panel). When differences in

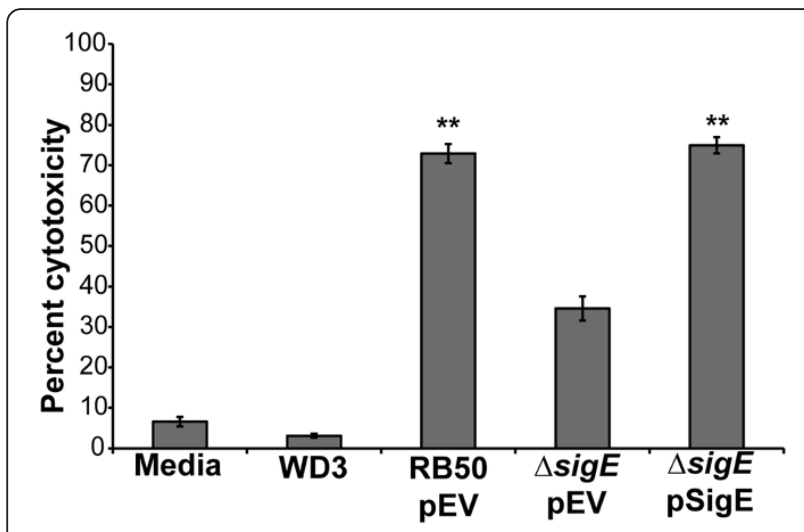

Figure 5 RB50 $\Delta$ sigE is less cytotoxic to macrophages than RB50. RAW 264.7 cells were incubated at an MOI of 10 with medium containing RB50 pEV, RB50 $\triangle$ sigE pEV, RB50 $\triangle$ sigE pSigE, TTSS-deficient RB50 strain WD3, or medium alone for 4 hours in the presence of $1 \mathrm{mM}$ IPTG to induce expression of sigE from the pLac promoter of pSigE. The average percent cytotoxicity of four wells in four separate experiments as measured by (LDH release from a well/ $\mathrm{LDH}$ release from the positive control well) $\times 100 \pm \mathrm{SE}$ is shown. The differences in percent cytotoxicity between RB50 $\triangle$ sigE pEV and either RB50 pEV or RB50 $\triangle$ sigE pSigE are statistically significant (** indicates $P$ value $<0.01$ ), while the cytotoxicities of RB50 pEV and RB50 $\triangle$ sigE pSigE are not significantly different.

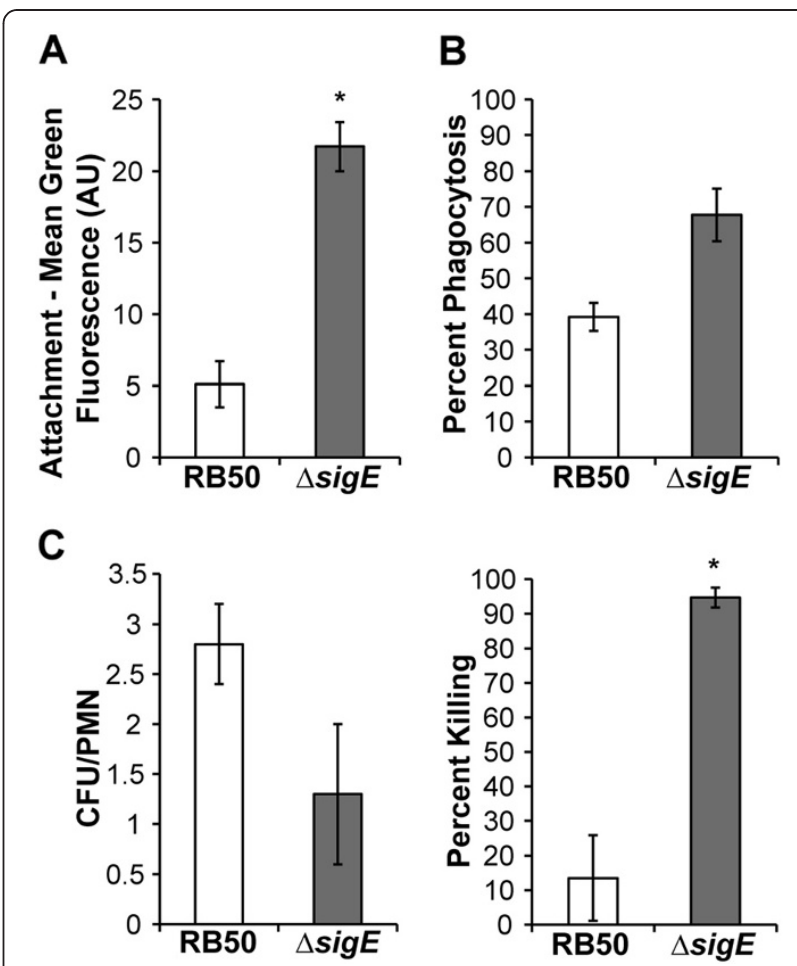

Figure 6 RB50 $\Delta$ sigE is more efficiently phagocytosed and killed by PMNs than RB50. (A) GFP-expressing RB50 (white bars) and RB50 $\Delta$ sigE (grey bars) were incubated with freshly isolated human peripheral blood PMNs for $20 \mathrm{~min}$ at an $\mathrm{MOI}$ of 50 . Attachment levels were measured as mean intensities \pm SE of green fluorescence associated with PMNs. (B) Cell surface-bound bacteria were detected by incubation with RPE-labeled goat $F\left(a b^{\prime}\right) 2$ fragments of anti-mouse IgG, after incubation with immune serum. Mean phagocytosis levels \pm SE were calculated from the decrease in red fluorescence of GFP-positive cells incubated for an additional $30 \mathrm{~min}$ at $37^{\circ} \mathrm{C}$ allowing for internalization (RPE2, 50 min total incubation time) compared to that of cells incubated for only 20 min (RPE1). Percent phagocytosis is (1-RPE2/RPE1) $\times 100 \%$. (C) To determine killing of bacteria by PMNs, cells incubated with bacteria for 50 min were treated with antibiotics to kill extracellular bacteria. Viable bacteria per PMN (left) and percent killing of internalized bacteria (right) were expressed as mean \pm SE. AU indicates arbitrary units; * indicates a P-value of $<0.05$.

attachment and phagocytosis were taken into consideration, significantly more internalized RB50 $\Delta$ sigE were killed compared to RB50 (Figure 6C, right panel). Together, these data indicate that SigE contributes to $B$. bronchiseptica resistance to phagocytosis and killing by PMNs.

\section{Discussion}

The BvgAS system of the bordetellae plays a central role in regulating gene expression during pathogenesis [50-52]. However, other regulators may be required during the infectious disease cycle, as Bordetella genomes have a large number of putative sensory systems 
[10,16-20]. In this study, we focused on cell envelope sensing systems and investigated the alternative sigma factor, SigE. We found that SigE of B. bronchiseptica does indeed mediate a protective cell envelope stress response and that strains lacking SigE do not establish lethal infections in mice lacking adaptive immunity. These data suggest that the role of SigE is to combat stresses to the envelope imposed by the immune system within a host and by harsh conditions in the environment outside a host. This work is the first demonstration of a cell envelope sensing system in the bordetellae. The $\sigma^{\mathrm{E}}$ system has been explored in the most depth in enteric pathogens belonging to the Gammaproteobacteria $[23,25,53]$. The bordetellae, members of the Betaproteobacteria, encounter distinctly different environments in the respiratory tract and therefore provide an excellent model to study how the SigE system has been adapted throughout evolution to serve the needs of diverse bacterial pathogens.

The entire sigE locus (BB3752-BB3750) is identical at the amino acid sequence level among the classical bordetellae, suggesting a conserved role in the human pathogens B. pertussis and B. parapertussis. However, the lifestyles and, therefore, conditions encountered differ amongst these three species. B. bronchiseptica can live outside the host and primarily infects mammals, although it can infect immunocompromised humans $[11,14]$. In contrast, B. pertussis and B. parapertussis primarily infect humans and are directly transmitted between hosts $[54,55]$. As we learn more about the role of SigE in the bordetellae, it will be of interest to determine whether stresses that induce the SigE system and the SigE regulon members are as highly conserved as the sigE locus itself among the bordetellae.

Our results define roles for SigE in B. bronchiseptica that are only partially overlapping with those for $\sigma^{E}$ in other pathogens. SigE was important for survival of $B$. bronchiseptica in the face of both global stresses to the cell envelope caused by heat shock, exposure to ethanol and detergent, and specific stresses caused by several beta-lactam antibiotics (Figure 2). Heat shock, ethanol, and detergent are classical stressors used in the laboratory to mimic conditions that lead to unfolded proteins and disrupted lipids during infection and in the environment. In contrast to the B. cenocepacia and S. Typhimurium proteins, B. bronchiseptica SigE was not required for survival during osmotic stress [6,36]. SigE was also not required for response to oxidative stress or the antimicrobial peptide polymyxin $\mathrm{B}$, unlike the $S$. Typhimurium $\sigma^{\mathrm{E}}$ ortholog $[6,29]$. The variations among bacteria in their use of $\sigma^{\mathrm{E}}$ systems likely reflect both differences in stresses encountered in environmental reservoirs and in particular host tissues during infection, as well as differences in the arrays of additional cellular stress responses possessed by each species. These other responses can act along with or in place of $\sigma^{\mathrm{E}}$. The presence of other stress responses may be particularly pertinent to $B$. bronchiseptica. Its genome is predicted to encode six related ECF sigma factors of unknown function in addition to SigE [24] that may have complimentary and redundant functions with SigE. Future studies defining conditions that activate other ECF sigma factors and their roles in B. bronchiseptica pathogenesis will provide a more comprehensive understanding of how $B$. bronchiseptica copes with extracytoplasmic stress.

Stress response systems, like the $\sigma^{\mathrm{E}}$ system, rapidly induce the expression of specialized sets of genes. These systems are often tightly regulated and expressed only when needed, because inappropriate expression of their regulons can interfere with other important cellular functions $[8,56,57]$. We found that SigE was not required for colonization and persistence of RB50 within the respiratory tract of an immunocompetent host (Figure 3), the primary niche of $B$. bronchiseptica. This result suggests that the pathogen does not encounter stresses in the respiratory tract that require a response by the SigE system. However, B. bronchiseptica encounters different challenges during infection in Rag1 ${ }^{-/-}$mice lacking $\mathrm{B}$ and $\mathrm{T}$ cells. In these mice, the infection spreads to the bloodstream, which is under greater immune surveillance and has a different arsenal of antimicrobial factors to attack invaders than the respiratory tract. The defect of RB50 $\operatorname{sig} E$ in lethal infection of $\operatorname{Rag} 1^{-/-}$mice, therefore, reveals a specific function for SigE in response to an unknown stress, possibly related to the innate immune response, that the bacteria encounter during infections that proceed beyond colonization of the respiratory tract.

The inability of RB50 $\Delta s i g E$ to cause lethal infections in Rag $1^{-1-}$ mice (Figure 4) could be due to failure to enter or survive in the bloodstream and/or systemic organs of these mice. Since the mutation does not affect survival during incubation with serum in vitro, it is unlikely that the sigE-deficient strain is more susceptible to complement or other antimicrobial components in serum. The defect in infection of $\mathrm{Rag}^{-/-}$mice may then be related to altered interactions of the mutant strain with phagocytic cells in the bloodstream. RB50 $\Delta$ sigE is more susceptible to peripheral blood PMNs than RB50 (Figure 6), and is also less cytotoxic to macrophages than RB50 (Figure 5). Either or both of these defects could explain the failure to recover RB50 $\Delta$ sigE from systemic organs of mice lacking adaptive immune responses and the decreased virulence in these mice.

Why does the RB50 $\Delta$ sigE mutant spread systemically and cause lethal infection in TLR $4^{\text {def }}$ and TNF- $\alpha^{-/-}$mice, but not $\operatorname{Rag} 1^{-1-}$ mice? The lower cytotoxicity of the sigE mutant and its increased sensitivity to phagocytic killing 
does not affect its virulence in mice lacking innate immune functions. This could be because bacterial numbers within the respiratory tract of TLR $4^{\mathrm{def}}$ or TNF- $\alpha^{-1-}$ mice are nearly an order of magnitude higher than in the lungs of Rag1 $1^{-1-}$ mice. As such, the large number of bacteria in $\mathrm{TLR}^{\text {def }}$ or $\mathrm{TNF}-\alpha^{-/-}$mice may overwhelm limiting host antimicrobial defense mechanisms that can contain the lower bacterial numbers in the lungs of Rag1 $1^{-/-}$mice. Alternatively, although the cytotoxicity of the $\operatorname{sig} E$ mutant is reduced, it may still be sufficient to establish lethal infections in the absence of TLR4 or TNF- $\alpha$. Thus TLR4- and TNF- $\alpha$-dependent functions, such as efficient phagocytosis and killing, appear to be sufficient to prevent lethal infection by RB50 $\Delta$ sigE in $R a g 1^{-1-}$ mice. Although the exact role remains to be elucidated, our results clearly indicate that SigE is required for lethal infection of mice lacking B and T cells.

Although the B. bronchiseptica strain RB50 causes asymptomatic infections in immunocompetent mice, other strains of $B$. bronchiseptica can cause a wide range of disease severity in other hosts [11-13]. In particular subsets of immunocompromised humans, such as those infected with HIV, severe systemic B. bronchiseptica infections have been observed [14]. These facts, along with the high degree of sequence conservation for the sigE locus in B. pertussis and B. parapertussis, highlights

Table 1 Strains and plasmids

\begin{tabular}{|c|c|c|c|}
\hline & Strain name & Genotype & Source, Reference \\
\hline \multirow[t]{8}{*}{ E. coli } & SEA001 & 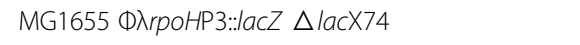 & {$[60]$} \\
\hline & SEA5036 & BL21(DE3) $\triangle$ slyD::kan pLysS pPER76 & {$[61]$} \\
\hline & XQZ001 & BL21(DE3) $\triangle$ slyD::kan pLysS pXQZ001 & This work \\
\hline & SEA4114 & CAG43113 $\triangle r p o E:: k a n \triangle$ nadB::Tn10 & {$[62]$} \\
\hline & SEA008 & SEA001 pTrc99a & {$[62]$} \\
\hline & SEA5005 & SEA001 pSEB006 & This work \\
\hline & XQZ003 & DH5a pXQZ0003 & This work \\
\hline & SS1827 & DH5a pSS1827 & [63] \\
\hline \multirow[t]{23}{*}{ B. bronchiseptica } & RB50 & RB50 & {$[58]$} \\
\hline & SEA5516 & $\mathrm{RB} 50 \triangle \operatorname{sig} E$ & This work \\
\hline & MER001 & RB50 pCW505 & This work \\
\hline & MER002 & RB50 $\triangle$ sigE pCW505 & This work \\
\hline & SEA5518 & RB50 pEV & This work \\
\hline & SEA5520 & $\mathrm{RB} 50 \triangle$ sigE $\mathrm{pEV}$ & This work \\
\hline & SEA5526 & RB50 pSigE & This work \\
\hline & SEA5530 & RB50 $\triangle$ sigE pSigE & This work \\
\hline & $\mathrm{RB} 50 \triangle \mathrm{wbm}$ & RB50 $\triangle w b m B w b m C w b m D w b m E$ & [64] \\
\hline & WD3 & $\mathrm{RB} 50 \triangle b s c N$ & [49] \\
\hline & Plasmid name & Description & Source, Reference \\
\hline & pTrc99a & Vector, pBR322 ori, $\mathrm{Ap}^{\mathrm{R}}$ & Pharmacia \\
\hline & pSEB006 & sigE in pTrc99a & This work \\
\hline & pSEB015 & isolated rpoHP3 promoter in pRLG770, Ap ${ }^{R}$ & {$[61]$} \\
\hline & pPER76 & rpoE in T7 expression vector pET15b, Kan $^{R}$ & [65] \\
\hline & pXQZ001 & sigE in T7 expression vector pET15b, $\operatorname{Kan}^{R}$ & This work \\
\hline & pXQZ002 & $\triangle$ sigE in TOPO-TA vector & This work \\
\hline & pSS1827 & helper plasmid competent for mating, $A p^{R}$ & [63] \\
\hline & pSS3962 & Bordetella-specific allelic exchange vector, $\operatorname{Kan}^{R}$ & Stibitz, unpublished work \\
\hline & pXQZ003 & $\triangle$ sigE in pSS3962 & This work \\
\hline & $\mathrm{pEV}$ & Vector pJS72, $\Omega S p e c^{R}$ cassette replaced with $\mathrm{Cm}^{R}$ & This work \\
\hline & pSigE & sigE in $\mathrm{pEV}$ & This work \\
\hline & pCW505 & cytoplasmic expression of GFP & [66] \\
\hline
\end{tabular}


the importance of understanding the stressors that activate $\operatorname{SigE}$ and how the SigE system responds to them during infection.

\section{Conclusions}

In this work, we have demonstrated that the B. bronchiseptica extracytoplasmic function sigma factor, SigE, is important for surviving global stresses that affect the whole cell, such as heat shock and ethanol stress, specific stresses that target the cell envelope, such as betalactam antibiotics and SDS-EDTA, and in interactions with the host innate immune system, particularly phagocytes. During infection, SigE is not required for colonization of the respiratory tract of immunocompetent mice. However, it is needed for a specific set of functions associated with virulence, particularly those involved in surviving the innate immune response when the infection progresses in immunocompromised mice. Although SigE systems are widely conserved, the details as to which aspects are shared and which have diverged are complex. As evidence accumulates from studies in different bacteria, it is becoming apparent that these sensory modules are important for stress survival, particularly with respect to the cell envelope. However, the nature of the stresses that SigE systems combat varies. During infection, comparisons are even more difficult, since differences are seen not only amongst SigE systems from one pathogen to another, but also within different niches in the host or during the progression of disease for a single pathogen.

\section{Methods}

\section{Strains and media}

A complete list of strains used in this study can be found in Table 1. B. bronchiseptica strains are derivatives of the previously described B. bronchiseptica strain RB50 [58]. $B$. bronchiseptica was maintained on Bordet-Gengou (BG) agar (Difco) containing 10\% defibrinated sheep blood (Hema Resources) and $20 \mu \mathrm{g} / \mathrm{ml}$ streptomycin. In liquid culture, B. bronchiseptica was grown in StainerScholte broth [59] with aeration. Chloramphenicol was used at $20 \mu / \mathrm{ml}$ and IPTG at $1 \mathrm{mM}$ where noted. The RB50 $\Delta$ sigE mutant was constructed as described below. E. coli strains used to measure SigE activity are derivatives of MG1655 that carry the $\sigma^{\mathrm{E}}$ dependent rpoHP3::lacZ reporter (strain SEA001 [34]). E. coli strain BL21(DE3) pLysS was used to express constructs for protein purification. E. coli were grown in LB broth in a gyratory water bath with aeration. Ampicillin was used at $100 \mu \mathrm{g} / \mathrm{ml}$, tetracycline at $20 \mu \mathrm{g} / \mathrm{ml}$, and kanamycin at $15 \mu \mathrm{g} / \mathrm{ml}$ as needed for experiments with E. coli.

\section{Plasmid constructions}

All plasmids used in this study are listed in Table 1 and oligonucleotide sequences are given in Table 2. Plasmid pSEB006 was constructed to express sigE in E. coli. The sigE gene was amplified from RB50 genomic DNA with the primers SigEF and SigER and cloned into the expression vector pTrc99a under the control of the IPTGinducible trc promoter. To facilitate purification of SigE, the plasmid pXQZ001 was constructed by amplifying the sigE gene from RB50 genomic DNA using the primers HisSigEF and HisSigER. The resulting PCR product was cloned into the T7 expression vector pET-15b (Novagen), which adds a 6X-His tag to the N-terminus of recombinant proteins. To express sigE in B. bronchiseptica, sigE was amplified from RB50 genomic DNA using primers 72SigEF and 72SigER and ligated into the $\mathrm{XbaI}$ and XhoI sites downstream of the pLac promoter in $\mathrm{pEV}$ to create $\mathrm{pSigE}$. The expression vector $\mathrm{pEV}$ was constructed from the broad host range vector pJS72 by replacing the spectinomycin resistance gene with the cat gene encoding chloramphenicol resistance amplified from pKD3 [67] using primers 72ChlorF and 72ChlorR. The exchange of drug markers was necessary because RB50 is naturally resistant to spectinomycin. pEV and pSigE were moved into RB50 and RB50 $\Delta$ sigE through tri-parental mating on $\mathrm{BG}$ agar with $\mathrm{MgCl}_{2}$. Transconjugants were selected on BG containing $60 \mu \mathrm{g} / \mathrm{ml}$ streptomycin and $20 \mu \mathrm{g} / \mathrm{ml}$ chloramphenicol. Plasmid pCW505 (kindly supplied by Dr. Alison Weiss, Cincinnati, Ohio), which induces cytoplasmic expression of GFP without affecting growth or antigen expression, was used to visualize RB50 and RB50 $\Delta$ sigE in the phagocytosis assays described below [68].

\section{Construction of RB50 $\Delta$ sigE strain}

The sigE gene was deleted from RB50 using a Bordetellaspecific allelic exchange procedure to produce strain SEA5516. Primers used in the construction are listed in Table 2. A PCR product containing 637 bp proximal to the 5 ' end of sigE was amplified from RB50 genomic DNA using primers SigEKO_LeftF and SigEKO_LeftR. A nonoverlapping PCR product containing 534 bp proximal to the 3' end of sigE was amplified with primers SigEKO_RightF and SigEKO_RightR. The two fragments were digested with BamHI and ligated. The resulting construct was amplified with primers SigEKO_LeftF and SigEKO_RightR, cloned into the TopoTA vector (Invitrogen), and verified by sequencing to give plasmid pXQ002. In this deletion construct, the 528 bp central region of the $\operatorname{sig} E$ gene is deleted leaving $66 \mathrm{bp}$ at the $5^{\prime}$ end and $6 \mathrm{bp}$ at the $3^{\prime}$ end of the sigE gene. The deletion construct from pXQ002 was then cloned into the EcoRI site of the allelic exchange vector pSS3962 (Stibitz S., unpublished data) to generate pXQ003 and transformed into E. coli strain DH5 $\alpha$. Tri- 
Table 2 Primer sequences

\begin{tabular}{|c|c|c|}
\hline Primer name & Sequence $\left(5^{\prime}-3^{\prime}\right)$ & Source or Reference \\
\hline SigEF & GGCGGAGAATTCAGGAGGAGGCGTCATGAGCGAACGCGATG & This work \\
\hline SigER & GGCCTAGGATCCTTACCAGCGACGCTCGGCAT & This work \\
\hline HisSigEF & GGCCTGGCATATGAGCGAACGCGATGTCGA & This work \\
\hline HisSigER & GGCCTAGGATCCTTACCAGCGACGCTCGGCAT & This work \\
\hline 72SigEF & GCGCGGTCTAGAAGGAGGAGGCGTCATGAGCGAACGCGATG & This work \\
\hline 72SigER & GCCCGGCTCGAGTTACCAGCGACGCTCGGCAT & This work \\
\hline 72 Chlorf & GCGGCGGGATCCTGTGTAGGCTGGAGCTGCTTC & [67] \\
\hline 72ChlorR & GCCGCCGGATCCCATATGAATATCCTCCTTA & [67] \\
\hline SigEKO_LeftF & GGGAATTCAAGATCGAGATCGGCCTGTCGAAT & This work \\
\hline SigEKO_LeftR & AGGGATCCGAAGGCTTTCTTGTCGCCACGTTGTA & This work \\
\hline SigEKO_RightF & AGGGATCCTGGTAAGGAGTGGCAGTCATGCAA & This work \\
\hline SigEKO_RightR & GCGAATTCAAAGCAACGGTGTCATCAACGTCC & This work \\
\hline PFamF & GGGCGGGAATTCTGCCGTTCGTGGATGTCCAG & This work \\
\hline PFamR & GGGCGGAAGCTTGGGCCAACGAACTACTGGGT & This work \\
\hline
\end{tabular}

parental mating with wild-type $B$. bronchiseptica strain RB50, E. coli strain DH5 $\alpha$ harboring the pXQ003 vector (strain XQ003), and DH5 $\alpha$ harboring the helper plasmid pSS1827 (strain SS1827) [69,70] and selection of mutants were performed as previously described [69]. The deletion strain was verified by PCR using primers SigEKO_LeftF and SigEKO_RightR and by Southern blot analysis.

\section{$\beta$-galactosidase assays}

Overnight cultures were diluted into fresh medium and grown to an $\mathrm{OD}_{600}$ of $0.1-0.2$ at $30^{\circ} \mathrm{C}$. Where indicated, IPTG was added to a final concentration of $1 \mathrm{mM}$. Samples were collected 2.5 hours later and $\beta$-galactosidase activity from the $\sigma^{\mathrm{E}}$-dependent reporter was assayed as previously described $[60,71]$.

\section{Complementation of $E$. coli $\triangle r p o E$ by $B$. bronchiseptica sigE}

The ability of $B$. bronchiseptica sigE to suppress the lethality caused by deletion of rpoE in $E$. coli was determined using a cotransduction assay as described [62]. The $\Delta r p o E:: k a n \quad \Delta$ nadB::Tn10 allele from strain SEA4114 was moved via P1 transdution into strain SEA5005, which carries sigE on the plasmid pSEB006. Tet-resistant $\left(\right.$ tet $\left.^{\mathrm{R}}\right)$ transductants were selected and then screened for kanamycin resistance $\left(\operatorname{kan}^{\mathrm{R}}\right)$. Although the $n a d B$ and rpoE alleles are tightly linked (>99\%), cotransduction resulting in tet $^{\mathrm{R}} \mathrm{kan}^{\mathrm{R}}$ colonies will only occur if $r p o E$ is no longer essential for viability. In transductions with E. coli expressing sigE (strain SEA5005) as the recipient strain, 31 out of 32 tet $^{\mathrm{R}}$ transductants were also $\operatorname{kan}^{\mathrm{R}}$. In contrast, none of the 39 tet $^{\mathrm{R}}$ transductants were $\operatorname{kan}^{\mathrm{R}}$ when $E$. coli carrying the empty cloning vector (strain SEA008) was the recipient strain.

\section{Protein purification}

N-terminally His-tagged B. bronchiseptica SigE and E. coli $\sigma^{\mathrm{E}}$ were purified from strain XQZ001 and SEA5036, respectively, as previously described for E. coli $\sigma^{\mathrm{E}}$ [61]. Briefly, cells were grown at $25^{\circ} \mathrm{C}$ to an $\mathrm{OD}_{600}$ of 0.5 , at which point IPTG was added to induce protein production. Following 1.5-3 hours of induction, cells were harvested by centrifugation and resuspended in lysis buffer (20 mM Tris- $\mathrm{HCl} \mathrm{pH}$ 8.0, $500 \mathrm{mM} \mathrm{NaCl}, 20 \mathrm{mM}$ imidazole, $2.5 \mathrm{mM} \beta$-mercaptoethanol, $1 \mathrm{mM}$ PMSF). Resuspended cells were then lysed by sonication, and the lysate cleared by centrifugation. The supernatant containing soluble His-SigE was loaded onto a Ni-NTA column (Qiagen). Bound proteins were eluted with a stepwise gradient of 20,60, 100, and $200 \mathrm{mM}$ imidazole in column buffer (20 mM Tris- $\mathrm{HCl} \mathrm{pH} 8.0,500 \mathrm{mM}$ $\mathrm{NaCl}, 2.5 \mathrm{mM} \beta$-mercaptoethanol). Fractions containing SigE were pooled and dialyzed into $20 \mathrm{mM}$ Tris $-\mathrm{HCl}$ $\mathrm{pH} 8.0,50 \mathrm{mM} \mathrm{NaCl}$, and $2.5 \mathrm{mM} \beta$-mercaptoethanol.

\section{In vitro transcription}

$100 \mathrm{nM}$ E. coli core RNA polymerase (Epicentre) was incubated with $400 \mathrm{nM}$ His-SigE or His- $\sigma^{\mathrm{E}}$ in transcription buffer (40 mM Tris- $\mathrm{HCl} \mathrm{pH} 8.0,10 \mathrm{mM} \mathrm{MgCl}_{2}$, $50 \mathrm{mM} \mathrm{NaCl}, 1 \mathrm{mM}$ DTT, $0.1 \mu / \mathrm{ml} \mathrm{BSA}$ ) for $10 \mathrm{~min}$ at $30^{\circ} \mathrm{C}$ to form holoenzyme. Multi-round transcription reactions were initiated by addition of holoenzyme at a final concentration of $40 \mathrm{nM}$ sigma factor and $10 \mathrm{nM}$ core RNA polymerase, to prewarmed $\left(30^{\circ} \mathrm{C}\right)$ transcription mix containing $5.0 \mathrm{nM}$ supercoiled plasmid template pSEB015 [61] or $5.0 \mathrm{nM}$ linear Pfam template, 5\% glycerol, $200 \mathrm{mM}$ ATP, $200 \mathrm{mM}$ CTP, $200 \mathrm{mM}$ GTP, $10 \mathrm{mM}$ UTP, and $2.5 \mathrm{mCi}\left[\alpha-{ }^{32} \mathrm{P}\right] \mathrm{UTP}$ in transcription buffer. After $10 \mathrm{~min}$ at $30^{\circ} \mathrm{C}$, reactions were stopped by 
the addition of stop solution (80\% formamide, $20 \mathrm{mM}$ EDTA, $0.1 \%$ xylene cyanol, and $0.1 \%$ bromophenol blue). Samples were electrophoresed on $6 \%$ polyacrylamide gels containing $7.5 \mathrm{M}$ urea, and transcripts were visualized by phosphorimaging. The linear Pfam template was generated by amplification of the promoter region of the gene encoding $\sigma^{32}$ in RB50, fam, using the primers PFamF and PFamR (Table 2). The sequence logo in Figure $1 \mathrm{C}$ was generated using WebLogo version 2.8.2 (http://WebLogo.berkeley.edu, [72]).

\section{Disk diffusion assays}

B. bronchiseptica cultures in mid-log phase were diluted to $6 \times 10^{8} \mathrm{CFU} / \mathrm{ml}$ and spread on Stainer-Scholte agar plates to generate a lawn of bacteria. Disks containing $300 \mathrm{IU}$ polymyxin $\mathrm{B}, 10 \mu \mathrm{g}$ ampicillin, $100 \mu \mathrm{g}$ mecillinam, $750 \mu \mathrm{g}$ sodium dodecyl sulfate (SDS) and $2.9 \mu \mathrm{g}$ EDTA, $30 \mu \mathrm{g}$ aztreonam, $10 \mu \mathrm{g}$ imipenem, $10 \mu \mathrm{g}$ meropenem, $30 \mu \mathrm{g}$ chloramphenicol, $15 \mu \mathrm{g}$ erythromycin, $30 \mu \mathrm{g}$ kanamycin, $30 \mu \mathrm{g}$ nalidixic acid, $150 \mu \mathrm{g}$ rifampicin, $23.75 \mu \mathrm{g}$ sulfamethoxazole and $1.25 \mu \mathrm{g}$ trimethoprim, $30 \mu \mathrm{g}$ tetracycline, $3.0 \mu \mathrm{g}$ deoxycholate, $3 \%$ hydrogen peroxide, or $2 \%$ paraquat were applied to the plates and the zones of inhibition were measured after overnight incubation at $37^{\circ} \mathrm{C}$.

\section{Temperature and ethanol stress}

For temperature stress experiments, mid-log phase cultures of RB50 and RB50 $s i g E$ were diluted to an $\mathrm{OD}_{600}$ of 0.01 in fresh Stainer-Scholte broth and incubated at $37^{\circ} \mathrm{C}$ in a gyratory water bath with shaking. At an $\mathrm{OD}_{600}$ of 0.1 , cultures were either shifted to $40^{\circ} \mathrm{C}$ for adaptation or kept at $37^{\circ} \mathrm{C}$. After 90 minutes, all cultures were shifted to $50^{\circ} \mathrm{C}$, and survival was measured by plating and CFU counts. For ethanol stress experiments, midlog-phase cultures of the pertinent strains were subcultured into fresh Stainer-Scholte broth with or without $3 \%$ ethanol and incubated at $37^{\circ} \mathrm{C}$ in a gyratory water bath with aeration. Bacterial growth was measured by $\mathrm{OD}_{600}$.

\section{Complement killing assay}

Complement killing assays were performed as previously described [73]. Approximately 500 CFU of RB50, RB50 $\Delta s i g E$, and RB50 $\Delta w b m$ from mid-log phase cultures were incubated with $45 \mu \mathrm{l}$ of diluted serum from C57BL/6 mice or PBS (final volume for incubation was $50 \mu \mathrm{l}$ ) for 1 hour at $37^{\circ} \mathrm{C}$. Bacterial numbers before and after incubation were determined by plating and CFU counts. Each strain was assayed in triplicate.

\section{Cytotoxicity assay}

Cytotoxicity assays were performed as previously described [44]. Briefly, bacteria were added to RAW
264.7 murine macrophage cells at a multiplicity of infection (MOI) of 10 and incubated for four hours. Percent lactate dehydrogenase (LDH) release, a measure of cytotoxicity, was determined by using Cytotox96 Kit (Promega) according to the manufacturer's protocol.

\section{Phagocytosis and killing by polymorphonuclear leukocytes}

Attachment and phagocytosis of the B. bronchiseptica strains by peripheral blood polymorphonuclear leukocytes (PMNs) were evaluated as previously described with a few modifications [74]. Briefly, GFP-expressing bacteria were incubated with PMNs at an MOI of 50 for $20 \mathrm{~min}$ at $37^{\circ} \mathrm{C}$ to allow binding. After extensive washing to remove nonattached bacteria, an aliquot was maintained on ice to be used as a bacterial attachment control. The remaining PMNs were further incubated for $30 \mathrm{~min}$ at $37^{\circ} \mathrm{C}$ to allow internalization, at which point phagocytosis was stopped by placing PMNs on ice. Bacteria bound to the cell surface in both aliquots were detected by incubation with RB50 immune serum for $30 \mathrm{~min}$ at $4^{\circ} \mathrm{C}$, followed by incubation with R-phycoerythrin (RPE)-labeled goat $F\left(a b^{\prime}\right)_{2}$ fragments of anti-mouse IgG at $4^{\circ} \mathrm{C}$ for $30 \mathrm{~min}$. All incubations were done in the presence of $25 \%$ heat-inactivated human serum to prevent nonspecific binding of antibodies. After washing, ten thousand cells per sample were analyzed by flow cytometry. Attachment control samples were also analyzed by fluorescence microscopy using a DMLB microscope coupled to a DC 100 camera (Leica Microscopy Systems Ltd.). Green fluorescence intensity associated with PMNs maintained at $37^{\circ} \mathrm{C}$ for $20 \mathrm{~min}$ has previously been shown to represent bacterial attachment [74]. Phagocytosis was calculated from the decrease in mean red fluorescence intensity of GFP-positive PMNs after the $30 \mathrm{~min}$ incubation allowing for internalization, as previously described [75]. Percent phagocytosis was calculated as follows: $100 \times(1-\mathrm{RPE} 2 / \mathrm{RPE} 1)$, where RPE1 is the mean RPE-fluorescence of the GFP-positive cells after $20 \mathrm{~min}$ at $37^{\circ} \mathrm{C}$ (attachment control) and RPE2 is the mean RPE-fluorescence of the GFP-positive cells after $50 \mathrm{~min}$ (internalized bacteria) at $37^{\circ} \mathrm{C}$.

Killing of bacteria by PMNs was assessed as follows: after phagocytosis of the bacteria, $400 \mu \mathrm{g} / \mathrm{ml}$ polymyxin $\mathrm{B}$ and $350 \mu \mathrm{g} / \mathrm{ml}$ chloramphenicol were added to the PMNs for 1 hour to kill the remaining extracellular bacteria and assess intracellular survival. Serial dilutions of samples were plated to determine the number of viable intracellular bacteria per PMN. The relative percent survival of internalized bacteria was calculated from the relative phagocytosis index and taking into account the initial attachment level of each strain, as follows: percent bacterial killing $=[1-\mathrm{N} /(\mathrm{A} \times \mathrm{P})] \times 100$, where $\mathrm{A}=$ number of bacteria associated with $\mathrm{PMN}$ after $20 \mathrm{~min}$ at $37^{\circ} \mathrm{C}$ (determined by fluorescent microscopy), $\mathrm{P}=$ phagocytosis 
index (1-RPE2/RPE1), $\mathrm{N}=$ number of viable bacteria per cell after incubation with antibiotics. Control experiments to assess the efficacy of antibiotic bactericidal activity were performed in parallel. Briefly, samples of $5 \times 10^{8}$ bacteria were incubated with antibiotics for $30 \mathrm{~min}$ at $37^{\circ} \mathrm{C}$ and plated. This resulted in a $>99 \%$ decrease in CFU.

\section{Animal experiments}

C57BL/6J, B6.129 S-Tnf $\mathrm{m}^{\mathrm{m} 1 \mathrm{Gkl} / \mathrm{J}}\left(\mathrm{TNF}-\alpha^{-/-}\right)$, B6 129S7$\operatorname{Rag} 1^{\text {tm1Mom}} / \mathrm{J}\left(\operatorname{Rag}^{-/-}\right), \mathrm{C} 3 \mathrm{H} / \mathrm{HeOuJ}\left(\mathrm{TLR} 4^{\text {suf }}\right)$ and $\mathrm{C} 3 \mathrm{H} /$ $\mathrm{HeJ}$ (TLR4 ${ }^{\text {def }}$ ) mice were obtained from Jackson laboratories (Bar Harbor). All mice were bred in our Bordetellafree, specific pathogen-free breeding rooms at The Pennsylvania State University. For inoculation, mice were sedated with $5 \%$ isoflurane (Abbott laboratory) in oxygen and $50 \mu \mathrm{l}$ of PBS containing $10^{5}$ or $5 \times 10^{5} \mathrm{CFU}$ of the indicated bacteria were pipeted onto the external nares $[76,77]$. This method reliably distributes the bacteria throughout the respiratory tract [76]. Survival curves were generated by inoculating TLR $4^{\mathrm{def}}$, TNF- $\alpha^{-/-}$and Rag1 $1^{-/-}$ mice with either RB50 or RB50 $\Delta$ sigE. Mice suffering from lethal bordetellosis as determined by severe hunched posture, ruffled fur, extremely labored breathing and apathy were euthanized to prevent unnecessary suffering [47]. For quantifying bacterial load, mice were euthanized via $\mathrm{CO}_{2}$ inhalation, and lung, trachea, nasal cavity, spleen, liver and/or kidneys were excised. Tissues were homogenized in PBS, aliquots were serially diluted, plated, incubated at $37^{\circ} \mathrm{C}$ for 2 to 3 days, and CFU were determined. All protocols were reviewed by the university IACUC and all animals were handled in accordance with institutional guidelines (IACUC approval number: 31297).

\section{Statistical analysis}

The mean +/- standard error (SE) of the geometric mean was determined when appropriate and expressed as error bars. Two-tailed, unpaired Student's T-tests were used to determine statistical significance between groups. All experiments were performed at least twice with similar results.

\section{Authors' contributions}

SB and SA conceived and designed the molecular and stress experiments, which were performed by SB. XZ and EH conceived and designed the infection studies, which were performed by XZ. SH performed the cytotoxicity experiments and MR performed the phagocytosis experiments. $S B, X Z$, EH, and SA wrote the manuscript. All authors have read, contributed to editing, and approved the final manuscript.

\section{Acknowledgements}

We thank Dr. Scott Stibitz (FDA) for providing the allelic exchange vector pSS3962 and the helper plasmid pSS1827. We thank Dr. Kenneth Keiler (the Pennsylvania State University) for providing the plasmid pJS72. This work was supported by NIH grant GM083113 (E.T.H), in part by NSF grant MCB0347302 (S.E.A.) and a NSF Graduate Research Fellowship to S.E.B.

\section{Author details}

${ }^{1}$ Department of Biochemistry and Molecular Biology, Pennsylvania State University, 406 Althouse Laboratory, University Park, PA 16802, USA. ${ }^{2}$ Department of Veterinary and Biomedical Sciences, Pennsylvania State
University, W210 Millennium Science Complex, University Park, PA 16802, USA. ${ }^{3}$ current address: Department of Microbiology and Immunology, Harvard Medical School, 200 Longwood Ave, Boston, MA 02115, USA. ${ }^{4}$ CINDEFI (UNLP, CONICET La Plata), School of Science, La Plata University, La Plata, Argentina.

Received: 7 December 2011 Accepted: 25 June 2012

Published: 16 August 2012

\section{References}

1. MacRitchie DM, Buelow DR, Price NL, Raivio TL: Two-component signaling and gram negative envelope stress response systems. Adv Exp Med Biol 2008, 631:80-110.

2. Rowley G, Spector M, Kormanec J, Roberts M: Pushing the envelope: extracytoplasmic stress responses in bacterial pathogens. Nat Rev Microbiol 2006, 4:383-394.

3. Crouch ML, Becker LA, Bang IS, Tanabe H, Ouellette AJ, Fang FC: The alternative sigma factor sigma is required for resistance of Salmonella enterica serovar Typhimurium to anti-microbial peptides. Mol Microbiol 2005, 56:789-799.

4. Ernst RK, Guina T, Miller SI: Salmonella Typhimurium outer membrane remodeling: role in resistance to host innate immunity. Microb Infect 2001, 3:1327-1334.

5. Jongerius I, Ram S, Rooijakkers S: Bacterial complement escape. Adv Exp Med Biol 2009, 666:32-48.

6. Humphreys S, Stevenson A, Bacon A, Weinhardt AB, Roberts M: The alternative sigma factor, $\sigma^{E}$, is critically important for the virulence of Salmonella Typhimurium. Infect Immun 1999, 67:1560-1568.

7. Mathur J, Waldor MK: The Vibrio cholerae ToxR-regulated porin OmpU confers resistance to antimicrobial peptides. Infect Immun 2004, 72:3577-3583.

8. Raivio TL: Envelope stress responses and Gram-negative bacterial pathogenesis. Mol Microbiol 2005, 56:1119-1128.

9. Arico B, Gross R, Smida J, Rappuoli R: Evolutionary relationships in the genus Bordetella. Mol Microbiol 1987, 1:301-308.

10. Parkhill J, Sebaihia M, Preston A, Murphy LD, Thomson N, Harris DE, Holden MT, Churcher CM, Bentley SD, Mungall KL, et al: Comparative analysis of the genome sequences of Bordetella pertussis, Bordetella parapertussis and Bordetella bronchiseptica. Nat Genet 2003, 35:32-40

11. Goodnow RA: Biology of Bordetella bronchiseptica. Microbiol Rev 1980, 44:722-738.

12. Mattoo S, Cherry JD: Molecular pathogenesis, epidemiology, and clinical manifestations of respiratory infections due to Bordetella pertussis and other Bordetella subspecies. Clin Microbiol Rev 2005, 18:326-382.

13. Musser JM, Bemis DA, Ishikawa H, Selander RK: Clonal diversity and host distribution in Bordetella bronchiseptica. J Bacteriol 1987, 169:2793-2803.

14. Mazumder SA, Cleveland KO: Bordetella bronchiseptica bacteremia in a patient with AIDS. South Med J 2010, 103:934-935.

15. Madan Babu M, Teichmann SA, Aravind L: Evolutionary dynamics of prokaryotic transcriptional regulatory networks. J Mol Biol 2006, 358:614-633.

16. Brickman TJ, Vanderpool CK, Armstrong SK: Heme transport contributes to in vivo fitness of Bordetella pertussis during primary infection in mice. Infect Immun 2006, 74:1741-1744

17. Conover MS, Redfern CJ, Ganguly T, Sukumar N, Sloan G, Mishra M, Deora R: BpsR modulates Bordetella biofilm formation by negatively regulating the expression of the Bps polysaccharide. J Bacterio/ 2012, 194:233-242.

18. Jungnitz H, West NP, Walker MJ, Chhatwal GS, Guzman CA: A second twocomponent regulatory system of Bordetella bronchiseptica required for bacterial resistance to oxidative stress, production of acid phosphatase, and in vivo persistence. Infect Immun 1998, 66:4640-4650.

19. Vanderpool CK, Armstrong SK: Integration of environmental signals controls expression of Bordetella heme utilization genes. J Bacterio/ 2004, 186:938-948.

20. Zimna K, Medina E, Jungnitz H, Guzman CA: Role played by the response regulator Ris in Bordetella bronchiseptica resistance to macrophage killing. FEMS Microbiol Lett 2001, 201:177-180.

21. Paget MS, Helmann JD: The sigma70 family of sigma factors. Genome Biol 2003, 4:203.

22. Gruber TM, Gross CA: Multiple sigma subunits and the partitioning of bacterial transcription space. Annu Rev Microbiol 2003, 57:441-466. 
23. Helmann JD: The extracytoplasmic function (ECF) sigma factors. Adv Microb Physiol 2002, 46:47-110.

24. Staron A, Sofia HJ, Dietrich S, Ulrich LE, Liesegang H, Mascher T: The third pillar of bacterial signal transduction: classification of the extracytoplasmic function (ECF) sigma factor protein family. Mol Microbiol 2009, 74:557-581.

25. Missiakas D, Raina S: The extracytoplasmic function sigma factors: role and regulation. Mol Microbiol 1998, 28:1059-1066.

26. Alba BM, Gross CA: Regulation of the Escherichia coli sigma-dependent envelope stress response. Mol Microbiol 2004, 52:613-619.

27. Rhodius VA, Suh WC, Nonaka G, West J, Gross CA: Conserved and variable functions of the $\sigma^{\mathrm{E}}$ stress response in related genomes. PLOS Bio/ 2006, 4:e2.

28. Muller C, Bang IS, Velayudhan J, Karlinsey J, Papenfort K, Vogel J, Fang FC: Acid stress activation of the $\sigma^{\mathrm{E}}$ stress response in Salmonella enterica serovar Typhimurium. Mol Microbiol 2009, 71:1228-1238.

29. Testerman TL, Vazquez-Torres A, Xu Y, Jones-Carson J, Libby SJ, Fang FC: The alternative sigma factor $\sigma^{E}$ controls antioxidant defences required for Salmonella virulence and stationary-phase survival. Mol Microbiol 2002, 43:771-782.

30. Deretic V, Schurr MJ, Boucher JC, Martin DW: Conversion of Pseudomonas aeruginosa to mucoidy in cystic fibrosis: environmental stress and regulation of bacterial virulence by alternative sigma factors. J Bacteriol 1994, 176:2773-2780.

31. Rowen DW, Deretic V: Membrane-to-cytosol redistribution of ECF sigma factor AlgU and conversion to mucoidy in Pseudomonas aeruginosa isolates from cystic fibrosis patients. Mol Microbiol 2000, 36:314-327.

32. De Las Penas A, Connolly L, Gross CA: The $\sigma^{\mathrm{E}}$-mediated response to extracytoplasmic stress in Escherichia coli is transduced by RseA and RseB, two negative regulators of $\sigma^{\mathrm{E}}$. Mol Microbiol 1997, 24:373-385.

33. Heusipp G, Schmidt MA, Miller VL: Identification of rpoE and nadB as host responsive elements of Yersinia enterocolitica. FEMS Microbiol Lett 2003, 226:291-298.

34. Mecsas J, Rouviere PE, Erickson JW, Donohue TJ, Gross CA: The activity of $\sigma^{\mathrm{E}}$, an Escherichia coli heat-inducible sigma-factor, is modulated by expression of outer membrane proteins. Genes Dev 1993, 7:2618-2628.

35. De Las Penas A, Connolly L, Gross CA: $\sigma^{\mathrm{E}}$ is an essential sigma factor in Escherichia coli. J Bacteriol 1997, 179:6862-6864.

36. Flannagan RS, Valvano MA: Burkholderia cenocepacia requires RpoE for growth under stress conditions and delay of phagolysosomal fusion in macrophages. Microbiology 2008, 154:643-653.

37. $\mathrm{Yu} \mathrm{H}$, Schurr MJ, Deretic V: Functional equivalence of Escherichia coli $\sigma^{\mathrm{E}}$ and Pseudomonas aeruginosa AlgU: E. coli rpoE restores mucoidy and reduces sensitivity to reactive oxygen intermediates in algU mutants of P. aeruginosa. J Bacteriol 1995, 177:3259-3268

38. Bianchi AA, Baneyx F: Hyperosmotic shock induces the $\sigma^{32}$ and $\sigma^{\mathrm{E}}$ stress regulons of Escherichia coli. Mol Microbiol 1999, 34:1029-1038.

39. Mathur J, Davis BM, Waldor MK: Antimicrobial peptides activate the Vibrio cholerae $\sigma^{\mathrm{E}}$ regulon through an OmpU-dependent signalling pathway. Mol Microbiol 2007, 63:848-858.

40. Keith $L M$, Bender CL: AlgT $\left(\sigma^{22}\right)$ controls alginate production and tolerance to environmental stress in Pseudomonas syringae. J Bacteriol 1999, 181:7176-7184.

41. Korbsrisate S, Vanaporn M, Kerdsuk P, Kespichayawattana W, Vattanaviboon P, Kiatpapan P, Lertmemongkolchai G: The Burkholderia pseudomallei $\mathrm{RpoE}$ (AlgU) operon is involved in environmental stress tolerance and biofilm formation. FEMS Microbiol Lett 2005, 252:243-249.

42. Tomoyasu T, Mogk A, Langen H, Goloubinoff P, Bukau B: Genetic dissection of the roles of chaperones and proteases in protein folding and degradation in the Escherichia coli cytosol. Mol Microbio/ 2001, 40:397-413.

43. Kovacikova $G$, Skorupski $K$ : The alternative sigma factor $\sigma^{\mathrm{E}}$ plays an important role in intestinal survival and virulence in Vibrio cholerae. Infect Immun 2002, 70:5355-5362.

44. Harvill ET, Cotter PA, Yuk MH, Miller JF: Probing the function of Bordetella bronchiseptica adenylate cyclase toxin by manipulating host immunity. Infect Immun 1999, 67:1493-1500.

45. Mann PB, Elder KD, Kennett MJ, Harvill ET: Toll-like receptor 4-dependent early elicited tumor necrosis factor alpha expression is critical for innate host defense against Bordetella bronchiseptica. Infect Immun 2004, 72:6650-6658
46. Mann PB, Kennett MJ, Harvill ET: Toll-like receptor 4 is critical to innate host defense in a murine model of bordetellosis. J Infect Dis 2004 189:833-836.

47. Mann PB, Wolfe D, Latz E, Golenbock D, Preston A, Harvill ET: Comparative toll-like receptor 4-mediated innate host defense to Bordetella infection. Infect Immun 2005, 73:8144-8152.

48. Burns VC, Pishko EJ, Preston A, Maskell DJ, Harvill ET: Role of Bordetella O antigen in respiratory tract infection. Infect Immun 2003, 71:86-94.

49. Yuk MH, Harvill ET, Miller JF: The BvgAS virulence control system regulates type III secretion in Bordetella bronchiseptica. Mol Microbiol 1998, 28:945-959.

50. Bock A, Gross R: The BvgAS two-component system of Bordetella spp.: a versatile modulator of virulence gene expression. Int J Med Microb 2001, 291:119-130.

51. Cotter PA, Jones AM: Phosphorelay control of virulence gene expression in Bordetella. Trends Microbiol 2003, 11:367-373.

52. Mattoo S, Foreman-Wykert AK, Cotter PA, Miller JF: Mechanisms of Bordetella pathogenesis. Front Biosci 2001, 6:E168-E186.

53. Bashyam MD, Hasnain SE: The extracytoplasmic function sigma factors: role in bacterial pathogenesis. Infect Genet Evol 2004, 4:301-308.

54. Gerlach G, von Wintzingerode F, Middendorf B, Gross R: Evolutionary trends in the genus Bordetella. Microb Infect 2001, 3:61-72.

55. Porter JF, Parton R, Wardlaw AC: Growth and survival of Bordetella bronchiseptica in natural waters and in buffered saline without added nutrients. Appl Environ Microbiol 1991, 57:1202-1206.

56. Park SD, Youn JW, Kim YJ, Lee SM, Kim Y, Lee HS: Corynebacterium glutamicum $\sigma^{\mathrm{E}}$ is involved in responses to cell surface stresses and its activity is controlled by the anti-sigma factor CseE. Microbiology 2008, 154:915-923.

57. Sheehan BJ, Bosse JT, Beddek AJ, Rycroft AN, Kroll JS, Langford PR: Identification of Actinobacillus pleuropneumoniae genes important for survival during infection in its natural host. Infect Immun 2003, 71:3960-3970.

58. Cotter PA, Miller JF: BvgAS-mediated signal transduction: analysis of phase-locked regulatory mutants of Bordetella bronchiseptica in a rabbit model. Infect Immun 1994, 62:3381-3390.

59. Stainer DW, Scholte MJ: A simple chemically defined medium for the production of phase I Bordetella pertussis. J Gen Microbio/ 1970, 63:211-220.

60. Costanzo A, Ades SE: Growth phase-dependent regulation of the extracytoplasmic stress factor, $\sigma^{\mathrm{E}}$, by guanosine $3^{\prime}, 5^{\prime}$-bispyrophosphate (ppGpp). J Bacterio/ 2006, 188:4627-4634.

61. Costanzo A, Nicoloff H, Barchinger SE, Banta AB, Gourse RL, Ades SE: ppGpp and DksA likely regulate the activity of the extracytoplasmic stress factor $\sigma^{\mathrm{E}}$ in Escherichia coli by both direct and indirect mechanisms. Mol Microbiol 2008, 67:619-632.

62. Hayden JD, Ades SE: The Extracytoplasmic stress factor, $\sigma^{\mathrm{E}}$, is required to maintain cell envelope integrity in Escherichia coli. PLOS One 2008, 3:e1573.

63. Stibitz S, Aaronson W, Monack D, Falkow S: The vir locus and phase-variation in Bordetella pertussis. Tokai J Exp Clin Med 1988, 13(Suppl):223-226.

64. Preston A, Allen AG, Cadisch J, Thomas R, Stevens K, Churcher CM, Badcock KL, Parkhill J, Barrell B, Maskell DJ: Genetic basis for lipopolysaccharide O-antigen biosynthesis in bordetellae. Infect Immun 1999, 67:3763-3767.

65. Rouviere PE, De Las Penas A, Mecsas J, Lu CZ, Rudd KE, Gross CA: rpoE, the gene encoding the second heat-shock sigma factor, $\sigma^{\mathrm{E}}$, in Escherichia coli. EMBO J 1995, 14:1032-1042.

66. Schaeffer LM, McCormack FX, Wu H, Weiss AA: Bordetella pertussis lipopolysaccharide resists the bactericidal effects of pulmonary surfactant protein A. J Immunol 2004, 173:1959-1965.

67. Datsenko KA, Wanner BL: One-step inactivation of chromosomal genes in Escherichia coli K-12 using PCR products. Proc Natl Acad Sci U S A 2000, 97:6640-6645

68. Weingart $C L$, Broitman-Maduro G, Dean G, Newman S, Peppler M, Weiss AA: Fluorescent labels influence phagocytosis of Bordetella pertussis by human neutrophils. Infect Immun 1999, 67:4264-4267.

69. Buboltz AM, Nicholson TL, Weyrich LS, Harvill ET: Role of the type III secretion system in a hypervirulent lineage of Bordetella bronchiseptica. Infect Immun 2009, 77:3969-3977.

70. Stibitz S, Carbonetti NH: Hfr mapping of mutations in Bordetella pertussis that define a genetic locus involved in virulence gene regulation. J Bacteriol 1994, 176:7260-7266. 
71. Miller JH: Experiments in molecular genetics. Cold Spring Harbor, NY: Cold Spring Harbor Laboratory Press; 1972.

72. Crooks GE, Hon G, Chandonia JM, Brenner SE: WebLogo: a sequence logo generator. Genome Res 2004, 14:1188-1190.

73. Goebel EM, Wolfe DN, Elder K, Stibitz S, Harvill ET: O-antigen protects Bordetella parapertussis from complement. Infect Immun 2008, 76:1774-1780

74. Rodriguez ME, Hellwig SM, Hozbor DF, Leusen J, van der Pol WL, van de Winkel JG: Fc receptor-mediated immunity against Bordetella pertussis. J Immunol 2001, 167:6545-6551.

75. Rodriguez ME, Van der Pol WL, Van de Winkel JG: Flow cytometrybased phagocytosis assay for sensitive detection of opsonic activity of pneumococcal capsular polysaccharide antibodies in human sera. J Immunol Methods 2001, 252:33-44.

76. Harvill ET, Preston A, Cotter PA, Allen AG, Maskell DJ, Miller JF: Multiple roles for Bordetella lipopolysaccharide molecules during respiratory tract infection. Infect Immun 2000, 68:6720-6728.

77. Kirimanjeswara GS, Agosto LM, Kennet MJ, Bjornstad ON, Harvill ET: Pertussis toxin inhibits neutrophil recruitment to inhibit antibodymediated clearance of Bordetella pertussis. I Clin Invest 2005, 115:3594-3601.

doi:10.1186/1471-2180-12-179

Cite this article as: Barchinger et al.: sigE facilitates the adaptation of Bordetella bronchiseptica to stress conditions and lethal infection in immunocompromised mice. BMC Microbiology 2012 12:179.

\section{Submit your next manuscript to BioMed Central and take full advantage of:}

- Convenient online submission

- Thorough peer review

- No space constraints or color figure charges

- Immediate publication on acceptance

- Inclusion in PubMed, CAS, Scopus and Google Scholar

- Research which is freely available for redistribution 